\author{
UNIVERSIDADE DE SÃO PAULO \\ ESCOLA DE ENGENHARIA DE SÃO CARLOS \\ PROGRAMA DE PÓS-GRADUAÇÃO EM ENGENHARIA DE PRODUÇÃO
}

GISELI GONÇALVES DE OLIVEIRA

ANÁLISE DO DESEMPENHO DE FUNDOS DE INVESTIMENTO EM AÇÕES BRASILEIROS

São Carlos

2021 


\section{ANÁLISE DO DESEMPENHO DE FUNDOS DE INVESTIMENTO EM AÇÕES BRASILEIROS}

\section{Versão Corrigida}

Dissertação apresentada ao Departamento de Engenharia de Produção da Escola de Engenharia de São Carlos da Universidade de São Paulo como requisito para obtenção do título de Mestre em Ciências.

Área de concentração: Economia, Finanças Corporativas e Econometria

Orientador: Prof. Dr. Aquiles Elie Guimarães Kalatzis

São Carlos 
AUTORIZO A REPRODUÇÃO TOTAL OU PARCIAL DESTE TRABALHO, POR QUALQUER MEIO CONVENCIONAL OU ELETRÔNICO, PARA FINS DE ESTUDO E PESQUISA, DESDE QUE CITADA A FONTE.

Ficha catalográfica elaborada pela Biblioteca Prof. Dr. Sérgio Rodrigues Fontes da EESC/USP com os dados inseridos pelo(a) autor(a).

Oliveira, Giseli Gonçalves de

048a Análise do desempenho de fundos de investimento em ações brasileiros / Giseli Gonçalves de Oliveira; orientador Aquiles Elie Guimarães Kalatzis. São Carlos, 2020 .

\footnotetext{
Dissertação (Mestrado) - Programa de Pós-Graduação em Engenharia de Produção e Área de Concentração em Processos e Gestão de Operações -Escola de Engenharia de São Carlos da Universidade de São Paulo, 2020.

1. Fundos de Ações. 2. Desempenho. 3. Modelo de quatro fatores de Carhart. 4. Fator APB. I. Título.
}

Eduardo Graziosi Silva - CRB - 8/8907 


\section{FOLHA DE JULGAMENTO}

Candidata: Licenciada GISELI GONÇALVES DE OLIVEIRA.

Título da dissertação: "Análise do desempenho de fundos de investimento em ações brasileiros".

Data da defesa: 20/01/2021.

Comissão Julgadora

Prof. Associado Aquiles Elie Guimarães Kalatzis

(Orientador)

(Escola de Engenharia de São Carlos - EESC/USP)

Prof. Dr. Elton Eustáquio Casagrande

(Universidade Estadual Paulista "Júlio de Mesquita Filho"/UNESP-

Araraquara)

Prof. Associado Marcio Poletti Laurini

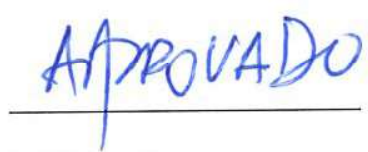

(Faculdade de Economia, Administração e Contabilidade de Ribeirão Preto/FEA-RP/USP)

Coordenadora do Programa de Pós-Graduação em Engenharia de Produção:

Profa. Dra. Janaina Mascarenhas Hornos da Costa

Presidente da Comissão de Pós-Graduação:

Prof. Titular Murilo Araujo Romero
Resultado

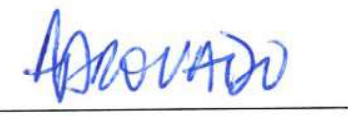



Dedico este trabalho especialmente aos meus pais por todo esforço, suporte e valores ensinados. Sou imensamente grata por serem meu maior exemplo de amor e carinho. 


\section{Agradecimentos}

Agradeço minha família por toda paciência e compreensão, mesmo quando eu passava meses sem visitá-los. O amor e suporte emocional de vocês foi muito importante nessa jornada.

Sou grata ao professor Aquiles pela paciência e orientação. Suas advertências, experiência e ensinamentos foram fundamentais para que eu pudesse realizar este trabalho e aprender mais sobre o tema proposto. Sou grata por todo aprendizado. Também não poderia deixar de agradecer à Aline por toda ajuda e boa vontade, muito obrigada.

Meus sinceros agradecimentos aos professores Fabiano e Márcio pelas sugestões e observações feitas no exame de qualificação. A contribuição de vocês foi valiosa para a finalização desta dissertação.

Agradeço aos queridos amigos do laboratório, que foram muito mais do que colegas de trabalho. Me ajudaram diariamente e tornaram os meus dias mais leves e alegres. Aprendi muito com todos vocês. Gostaria de agradecer especialmente pelo carinho, suporte e amizade da Karine. Sou profundamente grata por tê-la conhecido.

Gostaria de agradecer a todos os meus amigos, que transformaram essa difícil caminhada em momentos felizes e de crescimento. Agradeço especialmente aos queridos amigos Laura e Vinícius, por toda ajuda e amizade. Minha mais sincera gratidão.

Agradeço aos funcionários da Engenharia de Produção na EESC, que trabalham com tanto carinho e eficiência. Vocês viabilizam o desenvolvimento das pesquisas no departamento. Também não poderia deixar de agradecer ao suporte financeiro da CAPES e a todas as pessoas que direta ou indiretamente contribuíram para que fosse possível esta realização.

Minha imensa gratidão a todos por essa conquista. 
"Se quer alcançar resultados além dos que está obtendo, deve fazer além do que está disposto" Autor desconhecido 


\section{Resumo}

OLIVEIRA, Giseli Gonçalves. Análise do desempenho de fundos de investimento em ações brasileiros 2021. 87p. Dissertação (mestrado em ciências) - Escola de Engenharia de São Carlos, Universidade de São Paulo, São Carlos, 2021.

Este trabalho faz uma análise do desempenho dos fundos de ações brasileiros no período de 2009 a 2017. O modelo empregado é o de quatro fatores de Carhart, com o objetivo de entender as variáveis que contribuem com a geração de valor das carteiras desses fundos e auxiliar processos de investimento. Também foram feitas estimações adicionando ao modelo de Carhart um fator chamado de Active Peer Benchmarck (APB), relacionado às estratégias de investimento seguidas por alguns grupos dentro de cada categoria ANBIMA. Esse fator melhorou a significância da constante do modelo, usada na avaliação dos gestores dos fundos de investimento. Os dados foram coletados do NEFIN e da base de dados da Economática. A estimação foi feita em cross-section pelo método dos Mínimos Quadrados Ordinários com efeito fixo. Os resultados estimaram fatores que em sua maioria foram estatisticamente significantes, evidenciando a capacidade explicativa dos modelos para o mercado de ações brasileiro. Foi possível observar que no geral, o prêmio pelo risco do mercado apresentou maior rendimento. Além disso, apesar da evidência de habilidade superior dos gestores, algumas estratégias existentes entre as categorias acabaram por reduzir os ganhos, principalmente entre os fundos Específicos.

Palavras-chave: Fundos de Ações. Desempenho. Modelo de Quatro Fatores de Carhart. Fator APB. 


\begin{abstract}
Oliveira, Giseli Gonçalves Performance analysis of brazilian equity mutual funds 2021. 87 p. Dissertation (master of science) - School of Engineering of São Carlos, University of São Paulo, São Carlos, 2021.

This work analyzes the performance of Brazilian equity mutual funds in the period from 2009 to 2017. The model used is that of four factors of Carhart, with the objective of understanding the variables that contribute to the generation of value of the portfolios of these funds and to assist investment processes. Estimations were also made by adding to the Carhart model a factor called Active Peer Benchmarck (APB), related to the investment strategies followed by some groups within each ANBIMA category. This factor improved the significance of the model constant, used in evaluation of investment fund managers. Data were collected from NEFIN and from the Economática database. The estimation was made in cross-section using the Ordinary Least Squares method with fixed effect. The results estimated factors that for the most part were statistically significant, showing the explanatory capacity of the models for the Brazilian stock market. It was possible to observe that, in general, the market risk premium presented the highest return. In addition, despite the evidence of superior skills of the managers, some strategies existing between the categories ended up reducing the gains, mainly among the Specific funds.
\end{abstract}

Key words: Stock Mutual Funds. Performance. Carhart Four Factor Model. APB Factor. 


\section{Lista de figuras}

Figura 1 - Montagem das carteiras para o modelo de três fatores de Fama-French 27

Figura 2 - Carteiras usadas para o cálculo de SMB e HML . . . . . . . . . . . . 28

Figura 3 - Excesso de retorno médio anual dos fundos por categoria ANBIMA . 53

Figura 4 - Patrimônio líquido anual (em milhões de reais) . . . . . . . . . . . 81

Figura 5 - Captação líquida anual (em milhões de reais) e taxa CDI . . . . . . . . 81 


\section{Lista de tabelas}

Tabela 1 - Estatística Descritiva das Variáveis Usadas nos Modelos de Performance: de Janeiro de 2009 a Dezembro de 2017 . . . . . . . . . . . . . . 54

Tabela 2 - Correlação entre os fatores de risco do modelo de Carhart . . . . . . 57

Tabela 3 - Todos os fundos: resultados das regressões com modelo CAPM, 3 fatores de Fama-French e 4 fatores de Carhart . . . . . . . . . . . . . . . 59

Tabela 4 - Resultados das regressões com o modelo de quatro fatores de Carhart para os fundos de ações, agrupados por categoria ANBIMA. . . . . . 62

Tabela 5 - Percentual de fundos com coeficientes alfa estimados significativos e não significativos . . . . . . . . . . . . . . . . . . . . 67

Tabela 6 - Categoria Ativos: resultados das regressões para os fundos de ações com modelo CAPM, três fatores de Fama-French e quatro fatores de Carhart ....................... 84

Tabela 7 - Categoria Específicos: resultados das regressões para os fundos de ações com modelo CAPM, três fatores de Fama-French e quatro fatores de

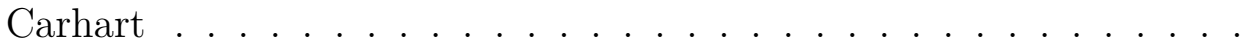

Tabela 8 - Categoria Indexados: resultados das regressões para os fundos de ações com modelo CAPM, três fatores de Fama-French e quatro fatores de Carhart ...................... 86

Tabela 9 - Categoria Investimento no Exterior: resultados das regressões para os fundos de ações com modelo CAPM, três fatores de Fama-French e quatro fatores de Carhart . . . . . . . . . . . . . 


\section{Lista de abreviaturas e siglas}

AIC Akaike Information Criterion

ANBIMA Associação Brasileira das Entidades dos Mercados Financeiro e de Capitais

APB Active Peer Benchmarck

APT Arbitrage Pricing Theory

BE Book Equity

BE/ME Book-to-market

BIC Bayesian Information Criterion

CAPM Capital Asset Pricing Model

CDI Certificado de Depósito Interbancário

CVM Comissão de Valores Mobiliários

HML High Minus Low

IIFA International Investment Funds Association

LCI Letras de Crédito Imobiliário

LCA Letras de Crédito do Agronegócio

ME $\quad$ Market Equity

MQO Mínimos Quadrados Ordinários

NEFIN Núcleo de Pesquisa em Economia Financeira

PIB Produto Interno Bruto

PL Patrimônio Líquido

SELIC Sistema Especial de Liquidação e Custódia

SMB Small Minus Big 
WML

Winners Minus Losers 


\section{Sumário}

Revisão de literatura . . . . . . . . . . . . . 20

2.1 Breve histórico dos modelos de fatores . . . . . . . . . . . . . . 22

2.2 Modelo com fator $A P B \ldots \ldots \ldots \ldots$

2.3 Mercado de fundos no Brasil . . . . . . . . . . . . . 34

2.4 Estrutura dos Fundos de Investimento no Brasil . . . . . . . . . . . 39

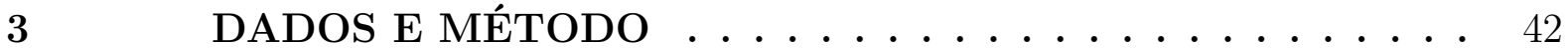

3.1 Descrição dos Dados . . . . . . . . . . . . . . . . . . . . 43

3.2 Metodologia e tratamento dos dados . . . . . . . . . . . 46

3.2.1 Modelo de Quatro Fatores de Carhart . . . . . . . . . . . . 47

3.2.2 Modelo de Carhart aumentado com fator APB . . . . . . . . . . . 49

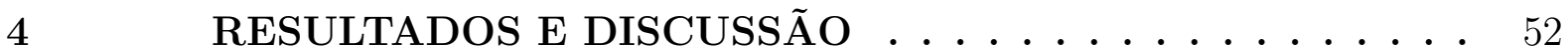

4.1 Estatística Descritiva: Variáveis dos Modelos . . . . . . . . 52

4.2 Resultados das Estimações . . . . . . . . . . . . 58

4.2.1 Parte I: CAPM, Fama-French e Carhart . . . . . . . . . . 58

$4.2 .2 \quad$ Parte II: Modelo com fator APB f . . . . . . . . . . . 66

Conclusão . . . . . . . . . . . . . . . . 71

$\operatorname{Referências}^{1} \ldots \ldots \ldots \ldots 75$

Apêndice A - Dados do histórico recente da indústria de fundos brasileira . . . . . . . . . . . 81

Apêndice B - Estrutura da nova classificação de fundos da

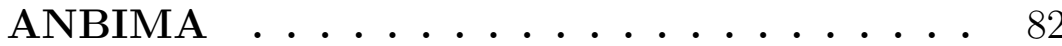

\footnotetext{
${ }^{1}$ De acordo com a Associação Brasileira de Normas Técnicas. NBR 6023.
} 
Apêndice C - Estimações dos modelos CAPM, três fatores de Fama-French e quatro fatores de Carhart por categoria ANBIMA ........... 84 


\section{Introdução}

Os fundos de investimento brasileiros constituem uma forma de condomínio, no qual os investidores compram cotas para que as aplicações sejam investidas coletivamente. Essa estrutura contribui com a redução de despesas e aumento do poder de diversificação da carteira, que passa a contar com uma gestão profissional na alocação dos recursos. $\mathrm{O}$ preço das cotas pode mudar diariamente, de acordo com a cotação dos títulos que compõe a carteira. A soma do valor de todas as cotas emitidas constitui o patrimônio líquido (PL) dos fundos. Cada fundo possui seu próprio regulamento que obedecendo às normas da Comissão de Valores Mobiliários (CVM), deve estabelecer regras, informar as despesas cobradas, a política de investimento, os objetivos e outras informações pertinentes.

De acordo com a International Investment Funds Association (IIFA, 2018), em 2015 o Brasil era a décima-primeira maior indústria de fundos de investimento do mundo. Apresentando crescimento constante mesmo diante de períodos de crise, o mercado brasileiro passou para a oitava posição no ranking mundial em dois anos, somando 3,4 trilhões de reais (1.9 trilhões de dólares) em patrimônio líquido, que representa 3,62\% do mercado mundial, superando países como Japão, China e Canadá. Ainda que modesta a participação dos fundos de ações no patrimônio líquido total da indústria (com 5,5\% do valor), observa-se que essa categoria tem acompanhado o crescimento do setor, acumulando 228 bilhões de reais no final de 2017 (Figura 4 do Apêndice A).

Apesar do aumento patrimonial apresentado, segundo relatório da Associação Brasileira das Entidades dos Mercados Financeiro e de Capitais $\left(\mathrm{ANBIMA}^{1}\right.$ ), os fundos brasileiros experimentaram forte queda na captação líquida (novas entradas de capital) entre os anos de 2013 a 2015. A entrada de novos recursos foi prejudicada pela recessão econômica, a alta nas taxas de juros e a atratividade de ativos de renda fixa isentos da cobrança de imposto de renda, como Letras de Crédito Imobiliário (LCI) e Letras de Crédito do Agronegócio (LCA). Nesse período a emissão dos títulos de renda fixa aumentou em $184 \%$, passando de 215,5 para 397,35 bilhões de reais. Com uma sinalização de recuperação econômica e a queda das taxas de juros, a partir de 2016 observou-se a retomada da captação líquida da indústria de fundos, que atingiu a marca histórica de mais de 263 bilhões de reais em 2017 (Figura 5 - Apêndice A).

\footnotetext{
${ }^{1}$ Disponível em: https://www.anbima.com.br/pt ${ }_{b} r /$ informar/estatisticas/fundos - de investimento/fi - consolidado - historico.htm
} 
O crescimento do patrimônio da indústria de fundos mostra que esses ativos têm se tornado cada vez mais atrativos para os investidores. Vantagens como possibilitar baixo investimento, diversificação da carteira, gestão profissional e especializada, diluição de custos, facilidade no pagamento de impostos e na avaliação do risco, além de fácil acompanhamento (devido ao envio periódico de relatórios) têm se mostrado bastante atrativas. Para que a indústria continue registrando aumento nas receitas, algumas barreiras ainda devem ser superadas. Diminuir a complexidade no processo de investimento e aumentar a compreensão da dinâmica do mercado são algumas delas, uma vez que análises superficiais podem fazer com que os investidores de varejo migrem para outros setores.

Visando facilitar o processo de investimento, aumentar a transparência do mercado e padronizar a indústria brasileira com a de grandes mercados internacionais, a ANBIMA (2015) publicou um paper técnico, apresentando a nova classificação para os fundos de investimento. O documento que entrou em vigor desde julho de 2015 divide os fundos em quatro classes: Renda Fixa, Ações, Multimercados e Cambial. Essas divisões por sua vez, alinharam e modernizaram as classes definidas anteriormente pela Instrução $\mathrm{n}^{\mathrm{o}}$ 555/14 da CVM. De acordo com a nova classificação, os fundos de ações (objeto desse estudo) devem possuir pelo menos $67 \%$ da carteira investida em ações de empresas brasileiras. As categorias que compõe essa classe podem variar pelo tipo de gestão (indexada ou ativa) e estratégia de investimento.

Entidades como ANBIMA e CVM buscam atuar também no sentido de orientar o investidor no processo de decisão. Segundo relatório da ANBIMA, a maior parte dos investidores têm uma clara noção do nível de risco que estão dispostos a assumir e do tempo que pretendem manter seus recursos aplicados, independente do volume destes. Trabalhos como Kahneman e Tversky (1979) e Pandelo Junior (2010) procuram entender o perfil e comportamento dos investidores, enquanto o modelo clássico de Neumann e Morgenstern (1944) baseia a tomada de decisão destes na busca da melhor relação entre risco e retorno, conforme conceito de fronteira eficiente formalizado por Markowitz (1952).

Uma análise superficial pode levar os investidores a escolherem aplicações que apresentam histórico de bom desempenho e menores taxas no entanto, existem muitos fatores que impactam nos resultados. O objetivo deste trabalho é compreender a relação entre o retorno dos fundos de ações brasileiros e os fatores de risco sistemáticos do modelo de quatro fatores de Carhart, para auxiliar nos processos de investimento. Como contribuição 
original às pesquisas sobre o desempenho de fundos brasileiros, adicionou-se também um fator relacionado às estratégias comuns de grupo (divididos por categoria ANBIMA), chamado Active Peer Benchmark (APB). Este fator é usado para aumentar a significância estatística dos parâmetros alfa estimados, melhorando a análise do desempenho dos gestores. O mercado dedica uma atenção especial à este tema, uma vez que alguns fundos cobram altas taxas de gestão e administração.

A amostra deste estudo contou com 1268 fundos de ações brasileiros em atividade no final de 2017. O período analisado foi de janeiro de 2009 a dezembro 2017. Valores referentes ao retorno dos fundos, taxas e regulamento (para consulta) foram retirados da base de dados da Economática. Os fatores de risco que compõe o modelo são disponibilizados pelo Núcleo de Pesquisa em Economia Financeira (NEFIN)2 ${ }^{2}$ Estes dados foram agrupados em painel não balanceado, no qual se aplicou regressão pelo método dos Mínimos Quadrados Ordinários (MQO) com efeito fixo para análise estatística.

O modelo de quatro fatores de Carhart foi escolhido pois como já verificado empiricamente pelo autor, explica melhor o retorno médio das carteiras de ações do que o tradicional modelo CAPM, que considera apenas o fator de risco do mercado. Os fatores adicionados procuram relacionar os retornos às características das empresas que os emitem. Dessa forma, o fator chamado Small minus Big (SMB) considera o tamanho da firma, medido pela capitalização de mercado (número de ações emitidas multiplicado pelo valor de cotação delas), enquanto o High minus Low (HML) usa o índice book-to-market (relação entre valor contábil e valor de mercado) e o Winners minus Losers (WML) faz referência ao desempenho dos ativos nos meses anteriores. Para melhorar a análise da habilidade dos gestores dos fundos, observada pelo coeficiente alfa do modelo, adicionou-se um fator chamado de Active Peer Benchmark (APB), que inclui o valor das taxas de administração cobradas e separa as estimações em grupos, com o objetivo de captar riscos idiossincráticos comuns aos fundos de mesma categoria ANBIMA.

Os resultados evidenciaram que as estimações feitas com o modelo de Carhart resultam em parâmetros significativos, que podem ser usados para explicar os possíveis fatores de risco presentes no mercado brasileiro de fundos de investimento. O impacto de cada um dos fatores mostrou estratégias que geram e destroem valor para os fundos.

\footnotetext{
${ }^{2} \mathrm{O}$ NEFIN foi desenvolvido por pesquisadores do Departamento de Economia da Faculdade de Economia, Administração e Contabilidade da Universidade de São Paulo. Tem se tornado referência para pesquisas sobre economia financeira no Brasil, fornecendo dados, relatórios, variáveis e indicadores calculados todos os dias desde 2001. Acesso pela página: www.nefin.com.br
} 
O APB mostrou melhorar a estimação dos alfas, aumentando a significância estatística dos coeficientes do modelo. Espera-se que este trabalho contribua com a avaliação do desempenho dos fundos brasileiros, evidenciando características que agregam ou destroem valor de acordo com as categorias ANBIMA, direcionando gestores e investidores de acordo com seu perfil e estratégia de investimento. 


\section{Revisão de literatura}

Esta seção exibe o contexto no qual a proposta deste trabalho está inserida. Será mostrada uma breve evolução histórica dos conceitos básicos que norteiam o entendimento atual sobre avaliação de ativos, com alguns dos principais modelos que relacionam o retorno obtido com fatores de risco sistemáticos. Motivada pelos numerosos trabalhos existentes em todo o mundo, ela discute algumas pesquisas e seus resultados. Como poderá ser notado, a maior parte dos trabalhos internacionais estuda o mercado dos Estados Unidos. Essa vasta literatura pode ser facilmente justificada devido ao seu tamanho, diversidade e eficiência. De acordo com dados do IIFA (2018), no final de 2017 o patrimônio líquido da indústria de fundos norte americana representava quase $50 \%$ da média mundial, sendo maior do que a da Europa toda somada.

A integração econômica resultante do processo de globalização dos mercados mundiais viabilizou o desenvolvimento do mercado financeiro brasileiro, composto pelo mercado de crédito, mercado monetário, mercado de câmbio e mercado de capitais, como explica CVM (2014). O mercado de crédito representa em geral financiamentos de curto e médio prazo, pelo qual instituições financeiras captam e emprestam recursos para empresas e pessoas físicas, assumindo os riscos dessas operações em troca de uma remuneração. A diferença entre a taxa de juros paga por essas instituições pela captação e concessão de capital é chamada de spread. O mercado monetário é formado por operações de curtíssimo prazo, como as realizadas entre bancos. É um instrumento de política monetária governamental, por meio do qual o Banco Central do Brasil ${ }^{1}$ intervém diretamente com a emissão e compra de títulos, alterando a liquidez econômica do país.

O mercado de câmbio é responsável pela compra e venda de moedas estrangeiras, sendo controlado pelo Banco Central por meio da política cambial e executado por instituições financeiras autorizadas. Já o mercado de capitais, ambiente no qual se desenvolve o assunto dessa pesquisa, é também uma ferramenta de desenvolvimento econômico. Composto por um complexo sistema de distribuição de valores mobiliários (ou títulos financeiros), viabiliza a capitalização de empresas, direcionando para elas os recursos de agentes superavitários. As operações realizadas no mercado de capitais são realizadas na

\footnotetext{
${ }^{1}$ Criado em 1965
} 
Bolsa de Valores (B3) ${ }^{2}$ e executadas por intermédio de instituições financeiras; fiscalizadas e regulamentadas pela $\mathrm{CVM}^{3}$. O mercado de capitais é utilizado como uma importante forma de captação de recursos, principalmente pelas grandes empresas (cerca de $70 \%$ das empresas brasileiras listadas na bolsa possuem faturamento superior a 400 milhões de reais). Outras vantagens da abertura de capital são a maior facilidade para aquisição e fusão, redução do risco de crédito (uma vez que o retorno dos investidores não é pré-definido e depende do desempenho da empresa), redução do custo de capital e maior liquidez patrimonial.

Um dos mecanismos de aquisição de valores mobiliários são as cotas dos fundos de investimento. Eles estimulam o investimento em títulos de renda variável, sendo uma ferramenta valiosa para o crescimento econômico do país. O primeiro documento oficial emitido pelo Ministério da Fazenda sobre fundos de investimento foi em 1959 (Sá, 1979) no entanto, diante de divergências conceituais, não existe um consenso sobre qual seria o primeiro fundo brasileiro. De acordo com Alves (2003) eles tiveram início no Brasil em 1952 com um fundo de condomínio fechado chamado Valéria Primeira, enquanto para Andrezo e Lima (2007) começou com o Fundo Crescinco em 1957, que foi o maior fundo de investimento em ações da América Latina no período (CVM, 2017).

Entre os anos de 2015 e 2016 a taxa de investimento em fundos de renda fixa era de $89 \%$ no Brasil, enquanto a média mundial era de 60\%. De acordo com CVM (2017) isso acontece porque o mercado brasileiro possui as maiores taxas de juros entre os países emergentes, estimulando o investimento em títulos de renda fixa. No entanto, o desenvolvimento das entidades, a ampliação das medidas regulatórias e a valorização no preço das ações proporcionaram o crescimento do mercado financeiro no país como um todo, como se pode notar diante do crescimento da indústria de fundos de ações.

Do ponto de vista dos investidores, os fundos são atrativos por possibilitarem diluição dos custos de transação, aplicações de pequenas quantias, facilidade de acompanhamento (devido ao envio periódico de relatórios) e pagamento de impostos, gestão profissional e diversificação da carteira. No entanto, apesar das vantagens oferecidas,

\footnotetext{
${ }^{2}$ Segundo o acervo digital da B3, o processo da criação da bolsa de valores no Brasil teve início em 1851 com alguns decretos imperiais. Em 1895 foi fundada a Bolsa de Fundos Públicos de São Paulo, que em 1967 passou a se chamar Bolsa de Valores de São Paulo (B3). No entanto, foi somente depois do ano 2000 que a B3 se tornou o único local de negociação de ações do país, após incorporar outras bolsas de valores, como a Bolsa do Rio de Janeiro. Em 2008 a bolsa brasileira se tornou uma das bolsas com maior valor de mercado no mundo.

${ }^{3}$ Criada em 1976
} 
investir ainda não é uma tarefa simples. Requer conhecimento, pesquisa e análise dos produtos de investimento, para a escolha do mais adequado. De acordo com Investment Company Institute (ICI, 2017), 92\% das pessoas investem em fundos para a aposentadoria, $46 \%$ para alguma emergência, $46 \%$ para reduzir a tributação sobre seus rendimentos e $22 \%$ são para investir em educação.

Conhecer a dinâmica do mercado é importante para escolher os ativos mais apropriados de acordo com os objetivos, necessidades, perfil e aversão ao risco de cada investidor. A indústria de fundos está amplamente relacionada com o mercado de ações, por isso seus rendimentos também são influenciados por fatores ligados às empresas de capital aberto, à economia e à política. Existem diferentes métodos e modelos para tentar explicar e fazer inferências sobre o retorno desses ativos. Este trabalho se baseia em alguns deles como Fama e French (1993), Carhart (1997) e Hunter et al. (2014), que apontam fatores de risco sistemáticos, com objetivo de entender o quanto cada classe de ativos está exposta a cada um eles.

\subsection{Breve histórico dos modelos de fatores}

A compreensão atual da relação entre risco e retorno foi estabelecida pela Teoria de Carteiras de Markowitz (1952). Ela diz que a diversificação pode reduzir o risco sistemático e mostra que existe uma carteira eficiente, na qual o investidor pode obter o maior retorno possível para um dado nível de risco assumido. Os princípios do autor para a otimização de carteiras de investimento e diminuição no desvio padrão dos retornos se tornaram as bases para os modelos de fatores, que procuram buscam explicar essas relações de maneira quantitativa.

O tradicional modelo de fator único (equação 1) que surgiu nesse contexto foi em decorrência de estudos formulados de maneira independente por Sharpe $(1964)^{4}$, Lintner (1965) e Traynor (1962) $)^{5}$. Amplamente difundido na área de finanças, ficou conhecido como Capital Asset Pricing Model (CAPM). O modelo consolidou as teorias apresentadas

\footnotetext{
${ }^{4}$ Dada sua contribuição no campo da economia financeira, Sharpe ganhou o Prêmio Nobel em Economia de 1990, juntamente com Markowitz e Merton Miller.

${ }^{5}$ Manuscrito não publicado, intitulado Toward a Theory of Market Value of Risky Assets. Uma versão final foi publicada em 1999, Asset Pricing and Portfolio Performance: Models, Strategy and Performance Metrics. Robert A. Korajczyk (editor) London: Risk Books, p. 15-22.
} 
por Markovitz, demonstrando com uma relação linear simples e prática a relação entre o retorno exigido de um ativo e uma carteira de mercado perfeitamente diversificada.

$$
R_{i}=R_{f}+\beta_{i} R M R F+\epsilon_{i}
$$

Em que $R_{i}$ é o retorno do ativo $i, R_{f}$ é o valor da taxa livre de risco e $\epsilon_{i}$ é o termo de erro. $R M R F$ é o fator de risco do modelo, calculado com uma média do retorno de todos os ativos negociados no mercado menos a taxa livre de risco $\left(R_{f}\right)$. O modelo de fator único atribui uma parte do retorno ao risco inerente do próprio ativo, enquanto a outra parte compõe o prêmio por um investimento igual ponderado em todos os ativos do mercado de referência (que está acima de um investimento de risco zero). O coeficiente beta da equação mostra o quanto o ativo $i$ é sensível às flutuações do mercado em que ele está inserido. Dessa forma, o modelo sugere que apenas um fator sistemático é capaz de explicar os retornos dos títulos.

O modelo CAPM entende que o retorno alcançado por meio de uma ação representa um custo de oportunidade, resultante da soma de uma taxa livre de risco com um prêmio pelo risco assumido no mercado. Ele assume portanto, que o retorno é totalmente explicado pelo risco da carteira de mercado. No entanto, uma carteira sob gestão ativa pode alcançar retornos diferentes do explicado pelo $\beta$ do mercado. Assim, a equação (1) não poderá mais possuir intercepto igual a zero, ficando como representado na equação (2), conforme explicou o trabalho de Jensen (1968). O autor mostrou que quando $\alpha$ é positivo e estatisticamente significante, indica que os gestores da carteira possuem habilidade para encontrar oportunidades com rendimentos acima do mercado. A medida não considera no entanto, o grau de diversificação da carteira ou risco adicional assumido. Assim, isolando o intercepto alfa na equação (2) tem-se um dos primeiros indicadores de desempenho do mercado, chamado Alfa de Jensen, usado na avaliação da habilidade dos gestores de uma carteira.

$$
R_{i}-R_{f}=\alpha_{i}+\beta_{i} R M R F+\epsilon_{i}
$$

Para estudar o retorno em ativos brasileiros, alguns autores como Castro e Minardi (2009) e Filho e Sousa (2015) usam a taxa SELIC (Sistema Especial de Liquidação e 
de Custódia) como $R_{f}$ nos modelos de fatores. A SELIC é a taxa básica de juros da economia, ambiente no qual os títulos do Tesouro Nacional (considerados isentos de risco) são negociados diariamente (SELIC efetiva) pelas instituições financeiras. Para controlar o volume de moeda em circulação e consequentemente a inflação, o governo estabelece que os bancos devem manter um valor diário em uma conta do Banco Central. Esse valor é negociado por meio de títulos públicos, com uma taxa de juros pré estabelecida pelo Comitê de Política Monetária do Banco Central (Copom). Por este motivo, existe um questionamento se a SELIC realmente representa uma boa proxi para $R_{f}$.

Por definição, a taxa livre de risco do CAPM deve ser uma taxa livremente negociada. Este trabalho usa o Certificado de Depósitos Interbancários (CDI) como $R_{f}$, uma vez que ele representa a taxa negociada livremente entre os bancos para fazerem empréstimos entre si e fecharem o caixa diariamente com saldo positivo. O valor da taxa CDI é calculado todos os dias pela B3, e costuma ser muito próximo da taxa SELIC. Rodrigues e Souza (1999) defendem o uso do CDI como ativo livre de risco, conforme usado nos trabalhos de Borges e Martelanc (2015), Laes e Silva (2014) e Nerasti e Lucinda (2016). No entanto, diante da vasta literatura encontrada sobre o tema, também se observa autores que testam seus resultados com mais de uma referência, usando a taxa CDI, a taxa SELIC e a taxa de poupança, como Rochman e Junior (2006) e Pinto (2014). O argumento dos autores para o uso da poupança como risck-free além do baixo risco, é sua fácil acessibilidade para o investidor comum.

Em virtude da sua essência teórica e baixa complexidade, existem algumas críticas quanto ao uso do CAPM. O ambiente de desenvolvimento do modelo requer a idealização do mercado de investimentos, necessária para inferir a existência de uma carteira totalmente eficiente. Dessa forma, ele ignora a existência de impostos e custos de transação, considera que todos os investidores possuem carteiras de risco idênticas, assume que a informação e expectativa dos investidores é homogênea e que estes, por preferirem retornos elevados com baixo risco, buscam racionalmente carteiras de média-variância.

Um exemplo de que o mercado não é "ideal"como presume o CAPM, é a existência da prática de arbitragem. Este nome é dado quando se consegue construir uma carteira de investimentos comprando e vendendo ativos com erro de precificação em diferentes mercados, obtendo lucro sem incorrer nenhum risco. Observando essa dinâmica no mercado norte americano, Ross (1976) desenvolveu a Teoria de Precificação por Arbitragem (APT 
- Arbitrage Pricing Theory), dando origem a um modelo linear flexível em que se pode fazer uso de mais de um fator de risco macroeconômico, ainda mantendo a premissa da diversificação de carteiras. Diferentemente dos outros modelos, a APT sugere a adição de fatores sistemáticos que produzem risco não diversificável sem apontar quantos e quais seriam eles.

Como já esperado no entanto, em pouco tempo o mercado entra em equilíbrio e a oportunidade de arbitragem se encerra. Quanto mais rápido o equilíbrio for estabelecido mais eficiente é considerado o mercado, demonstrando que existem outras fontes além da arbitragem para explicar retornos anormais. Dada a necessidade de encontrá-las, surgiram modelos com diferentes fatores como por exemplo: valor e crescimento, de Fama e French (1993); desempenho passado, de Carhart (1997); rentabilidade, de Novy-Marx (2013); padrão de investimento, de Aharoni, Grundy e Zeng (2013); inflação, de Chen, Roll e Ross (1986). Assim, em algumas décadas a literatura partiu de um modelo de fator único como o CAPM, para modelos com até oito fatores, como o de Grinblatt e Titman (1994).

Uma extensa pesquisa de Hwang e Rubesam (2018) contou com um universo de 83 fatores de risco, testando diferentes modelos para explicar o retorno de ações individuais. Os autores mostraram que poucos deles parecem ser efetivos de fato. No entanto, o poder explicativo do tradicional fator de mercado permaneceu o mais relevante. Chamando a atenção para essa proliferação de novos fatores de risco encontrada na literatura, Cochrane (2011) a apelidou de Zoológico de Fatores, ou Factor Zoo. Diante deste cenário, trabalhos como Feng, Giglio e Xiu (2017) e Hwang e Rubesam (2018) testam a contribuição de alguns desses fatores nos modelos de avaliação de ativos, enquanto Hsu e Kalesnik (2014) consideram que essa abundância de fatores serve apenas para fins de publicação, não contribuindo de forma prática para a avaliação dos investidores.

Observando o mercado de ações norte americano, Fama e French (1992) constataram que historicamente, é esperado que as empresas consideradas pequenas (com baixa capitalização de mercado) e as empresas de valor (alto índice book-to-market), apresentem retornos médios superiores. Para captar a influência empírica desse padrão, Fama e French (1993) conceberam dois fatores de risco que segundo os autores, quando somados ao fator de mercado do CAPM explicam parte significativa dos retornos dos ativos. O resultado foi a criação do tradicional e conhecido modelo de três fatores de Fama-French, também utilizado na orientação e desenvolvimento da pesquisa deste trabalho. 
Para entender a formação do modelo de Fama-French é necessário explicar alguns dos conceitos presentes na sua construção. O primeiro deles já foi citado acima, tratando-se da capitalização de mercado (ME), market capitalization ou market equity. O valor de ME é calculado pela multiplicação entre o número de ações emitidas por uma empresa e o preço de cada uma delas, ou seja, é o valor total das ações de uma empresa. Representando uma estimativa do valor de mercado de uma empresa, ME pode ser usado como proxy para como o mercado a entende e avalia. Uma vez que em números, existem muito mais empresas pequenas (baixo ME) do que empresas grandes (alto ME), a distribuição da capitalização de mercado se torna assimétrica. As ações de empresas com baixo ME são conhecidas como Small Caps, enquanto os ativos de empresas com alto ME são chamados de Blue Chips. O nome foi dado especulativamente pelo mercado por serem consideradas ações de primeira linha, fazendo referência às fichas azuis do pôquer que valem mais do que as outras. Inicialmente, as Blue Chips apresentavam os maiores preços da bolsa, no entanto, por serem os ativos mais negociados, hoje esse termo está mais associado à liquidez.

Outra definição importante é a o do índice book-to-market (ou BE/ME), calculado pela divisão entre o patrimônio líquido (PL) ou Book Equity (BE) e o valor de mercado, ME. Vale destacar que o PL é uma medida contábil retroativa, resultante do valor divulgado no balanço patrimonial de uma empresa menos o valor de sua dívida, ou seja, a diferença entre os ativos e passivos dessa empresa. Assim, o PL representa os investimentos passados, enquanto o valor de mercado representa uma estimativa das oportunidades futuras de crescimento. Em outras palavras, a relação BE/ME expressa a avaliação que o mercado faz de uma empresa diante dos seus relatórios contábeis, podendo revelar algum fator ligado à firma que não está registrado neles. Empresas com alto índice BE/ME são chamadas de empresas de valor, enquanto as que possuem baixo índice BE/ME são chamadas empresas de crescimento.

Para construir o modelo, Fama e French começaram ordenando as ações de empresas cotadas na NYSE (bolsa de valores norte americana que negocia ações de empresas com maior capitalização de mercado) por tamanho, a partir do valor de mercado (ME). Calcularam um valor médio de ME e dividiram a amostra em dois grupos. As empresas pequenas (Small), com ME abaixo do valor médio, e as empresas grandes (Big), com ME acima da média. Depois, as mesmas ações foram novamente ordenadas com base no índice 
$\mathrm{BE} / \mathrm{ME}$ e divididas em três grupos. As $30 \%$ com menor índice foram chamadas de Low, as $30 \%$ de maior índice chamadas de High e as $40 \%$ restantes chamadas de Medium. As intersecções entre esses grupos deram origem a seis carteiras $(\mathrm{B} / \mathrm{L}, \mathrm{B} / \mathrm{M}, \mathrm{B} / \mathrm{H}, \mathrm{S} / \mathrm{L}, \mathrm{S} / \mathrm{M}$, S/H), conforme ilustra a Figura 1, adaptada de Kilsgård e Wittorf (2011). O retorno de cada carteira é então calculado como a média do retorno de todas as ações que a compõe.

Figura 1 - Montagem das carteiras para o modelo de três fatores de Fama-French

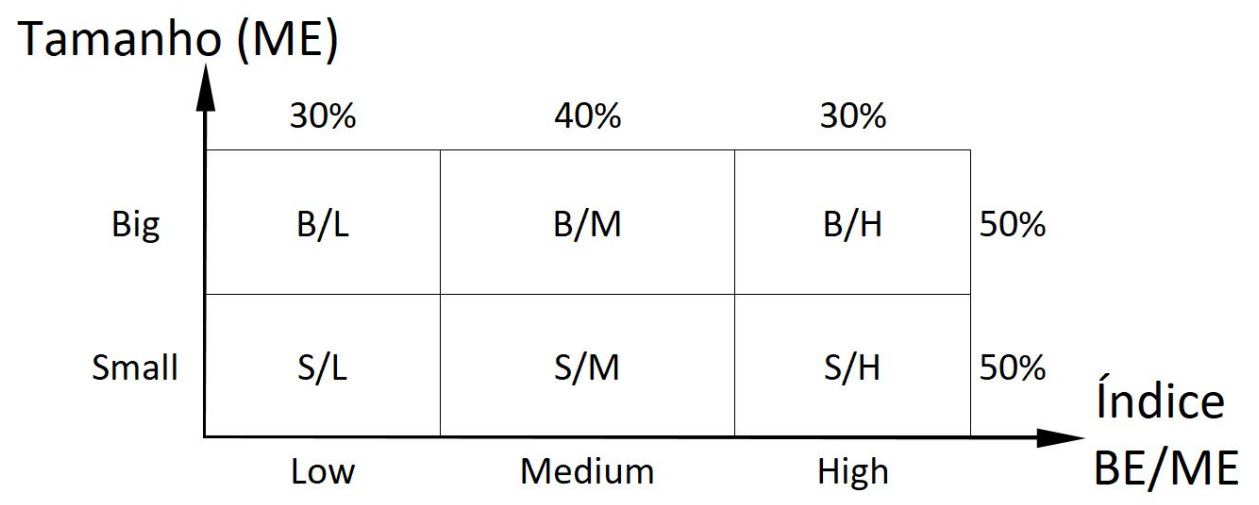

Fonte: Adaptado de Adaptado de Kilsgard e Wittorf (2011, p.13)

Os dois fatores de risco acrescentados ao CAPM por Fama e French (1993) são chamados de SMB (Small Minus Big) e HML (High Minus Low). Como se pode observar pela sua construção, o primeiro faz referência ao tamanho das empresas de acordo com o seu valor de mercado, enquanto o segundo se refere ao valor da empresa diante do mercado. O valor de SMB é dado por um terço do retorno das carteiras Small menos um terço do retorno das carteiras Big. HML é calculado como a soma entre o retorno das ações com alto índice BE/ME, menos as ações com baixo índice BE/ME, dividido por dois, conforme descrevem as equações (3) e (4).

$$
\begin{gathered}
S M B=\frac{1}{3}((S / L+S / M+S / H)-(B / L+B / M+B / H)) \\
H M L=\frac{1}{2}((B / H+S / H)-(B / L+S / L))
\end{gathered}
$$

A figura (2) ilustra a formação dos fatores de risco SMB e HML, conforme procedimento descrito. Em azul se observam as carteiras High (B/H, S/H) e Low (B/L, S/L), que compõe o cálculo de HML. Em vermelho estão as carteiras Small (S/L, S/M, S/H) e 
$\operatorname{Big}(\mathrm{B} / \mathrm{L}, \mathrm{B} / \mathrm{M}, \mathrm{B} / \mathrm{H})$, usadas para SMB.

Figura 2 - Carteiras usadas para o cálculo de SMB e HML

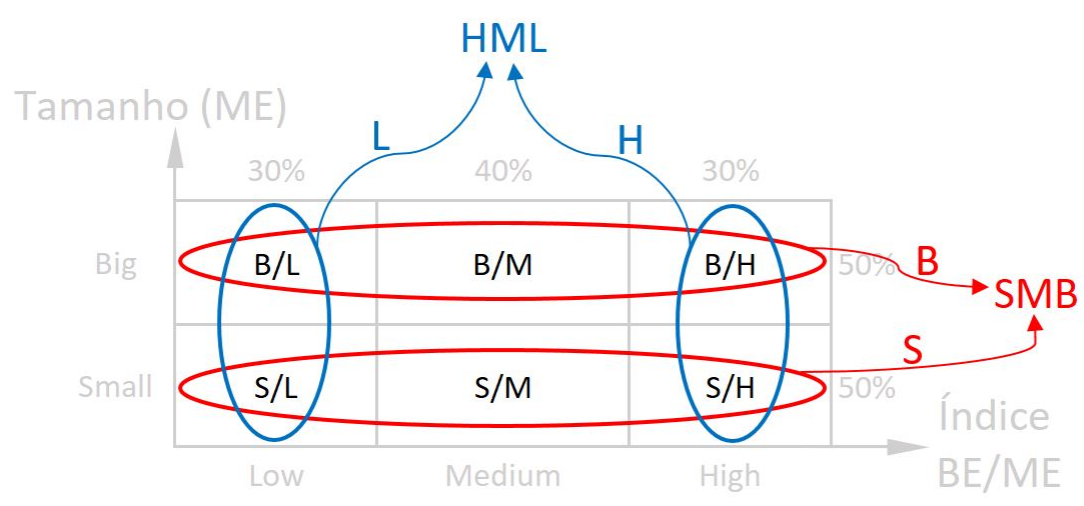

Fonte: Adaptado de Adaptado de Kilsgard e Wittorf (2011, p.13)

Como já observado, Fama e French notaram que os ativos das empresas com baixo ME (Small) e alto índice BE/ME (High) apresentavam melhor desempenho. Assim, de acordo com a construção do modelo, os autores esperaram encontrar valores positivos para os fatores de risco SMB e HML. Depois de construídos os fatores foram incluídos ao tradicional modelo CAPM, melhorando os resultados em comparação ao modelo de fator único, conforme afirma Carhart (1995). O modelo de três fatores de Fama-French ficou então estabelecido conforme representado na equação (5).

$$
R_{i t}-R_{f t}=\alpha_{i t}+\beta_{1 i t} R M R F_{t}+\beta_{2 i t} S M B_{t}+\beta_{3 i t} H M L_{t}+\epsilon_{i t}
$$

Na qual os subscritos $t$ representam os valores mensais calculados. $R_{i t}$ é o retorno do ativo $i, R_{f t}$ é a taxa livre de risco, RMRF é o retorno de todos os ativos negociados no mercado menos a taxa livre de risco, SMB e HML são os novos fatores sistemáticos e $\epsilon_{i t}$ é o termo de erro do modelo associado ao ativo $i$. A variável dependente $R_{i t}-R_{f t}$ é excesso de retorno (líquido das despesas), pois representa o valor adicional que um ativo criou ou perdeu com o risco assumido, quando comparado com um investimento isento de risco. De acordo com o CAPM apenas essa parte do retorno, que está acima da taxa livre de risco, representa uma remuneração pelo risco adicional assumido. Do outro lado 
da equação, os fatores são as variáveis explicativas, revelando as possíveis fontes dessa geração de valor e a influência que o desempenho das respectivas carteiras têm sobre o retorno do ativo estudado.

O poder explicativo do modelo de Fama-French foi testado em vários trabalhos no mundo todo, como Blanco (2012), Asness, Moskowitz e Pedersen (2013), Laes e Silva (2014) e Nerasti e Lucinda (2016), por exemplo. Apresentando resultados satisfatórios e superiores ao CAPM, o modelo continua bastante aceito no mercado. Assim, o modelo de Fama-French sustenta o conceito de que o retorno excedente esperado na carteira é resultado da soma entre três fatores sistemáticos: o prêmio pelo risco do mercado, a aplicação em empresas com menor valor de mercado e com maior índice BE/ME (uma vez que por construção empírica, espera-se que esses valores sejam positivos). Vale observar que no caso de esses fatores explicarem totalmente o retorno alcançado, o intercepto da equação (5) fica igual a zero, uma vez que ele representa a parcela de valor gerada pelos gestores da carteira, que não é explicada pelos fatores sistemáticos.

Jegadeesh e Titman (1993) também chegaram a uma conclusão interessante, estudando a dinâmica de compra e venda de ações no mercado. Os autores analisaram duas carteiras de investimento: uma formada por ativos que apresentaram bom desempenho nos meses anteriores, chamada de Winners, e outra formada por ativos que vinham performando mal, chamada de Losers. Observaram que ambas tinham predisposição para repetir o desempenho passado por alguns meses, e chamaram esse comportamento de momentum. Dessa forma, o trabalho mostrou que uma carteira formada com o retorno dos Winners menos o retorno dos Losers apresentou retornos positivos por cerca de 12 meses, no entanto, no longo prazo o resultado não se manteve.

Motivado pelo fato de o modelo de três fatores de Fama-French não explicar a persistência de performance dos ativos conforme documentada por Jegadeesh e Titman (1993), Carhart (1997) desenvolveu o modelo de quatro fatores de Carhart, adicionando mais um fator de risco ao modelo de três fatores de Fama-French. O quarto fator, chamado WML (Winners Minus Losers), foi construído para captar a ocorrência de momentum, explicando o trade-off existente entre o retorno e os outros fatores de risco. Primeiro as ações foram ordenadas pelo seu desempenho nos 12 meses anteriores, depois foi calculada a média do retorno das 30\% com melhor desempenho (Winners) e subtraída a média do retorno das $30 \%$ com menor desempenho (Losers), resultando no valor de WML. 
O novo fator de risco pode então ser entendido como uma tendência em o preço de uma ação continuar subindo quando está já está em alta e caindo quando já está em baixa. Carhart (1997) mostrou que o quarto fator aumenta o poder explicativo do modelo de Fama e French (1993) para desempenhos anormais. O autor também encontrou evidências de que fundos com bom desempenho tendem a manter seus resultados apenas por mais um ano, enquanto fundos com desempenho ruim tendem a assumir maiores riscos para compensar as perdas passadas, e acabam reproduzindo os resultados anteriores por um período maior. A representação do modelo de Carhart será detalhada na seção 3, onde se discorre sobre a metodologia empregada nesta pesquisa.

Brown e Goetzmann (1995), Hendricks e Zeckhauser (1993) e Goetzmann e Ibbotson (1994) encontraram evidências de persistência de performance dos fundos no curto prazo (de 1 a 3 anos) e a atribuíram à habilidade dos gestores ou estratégias de investimento comuns. No entanto, Carhart (1997) afirma que não se pode atribuir esse resultado aos gestores, pois no curto prazo ele seria consequência do fator de momentun. Diante das hipóteses mencionadas, Hunter et al. (2014) propõem adicionar um fator APB (Active Peer Benchmark) ao modelo de quatro fatores. O objetivo de fator APB é captar estratégias idiossincráticas comuns usadas por diferentes grupos, revelando se o retorno apresentado pelos fundos é apenas uma reprodução da categoria ou a consequência direta da habilidade superior na gestão.

\subsection{Modelo com fator $A P B$}

De acordo com Hunter et al. (2014) os fundos de investimento prometem criar valor por meio de uma gestão ativa especializada e para isso, fazem uso de estratégias semelhantes às dos seus pares. Grinblatt, Titman e Wermers (1995) afirmam que 77\% dos fundos usam a estratégia de momentum, comprando ações com bom desempenho passado. Chen, Jegadeesh e Wermers (2000) examinaram as carteiras dos fundos, e afirmaram que estes preferem comprar títulos com maior liquidez. No entanto, Kacperczyk, Sialm e Zheng (2008) apontam para uma lacuna existente entre os retornos obtidos pelos fundos e os retornos das carteiras divulgadas periodicamente por eles, gerando resultados imprecisos quando estas são consideradas em análises de desempenho. 
A dinâmica de pares evidenciada por Hunter et al. (2014) acaba produzindo resíduos correlacionados nos modelos de precificação comumente usados, dificultando a identificação dos gestores qualificados e não qualificados. Para resolver esse problema de forma mais simples (ao invés de tentar encontrar os possivelmente numerosos fatores exógenos que levam à formação das carteiras de investimento), os autores propõem a formação de uma referência (APB) a partir do retorno do grupo ao qual um fundo pertence. O objetivo dessa referência é captar vieses comportamentais equivalentes, uma vez que os gestores escolhem grupos semelhantes para competir. Com esse novo modelo, os autores mostraram uma redução substancial nas correlações residuais entre os fundos de mesma categoria estudados, melhorando significativamente os resultados para avaliação da gestão em um grupo de pares.

O procedimento usado por Hunter et al. (2014) para o cálculo e adição do fator APB ao modelo de quatro fatores de Carhart também está detalhado na seção 3, uma vez que este trabalho adotou metodologia semelhante para avaliação dos gestores dos fundos, que foi empregada nas quatro categorias de fundos de ações brasileiros.

Apesar da modesta participação japonesa, em 1990 o mercado de ações do Japão e Estados Unidos somados representavam $67 \%$ do total mundial. Motivados pelo contraste entre a baixa quantidade de estudos do mercado japonês e a extensa literatura sobre o mercado norte americano, Chan, Hamao e Lakonishok (1991) estudaram o retorno do mercado de ações no Japão de 1971 a 1988. Dentre as variáveis observadas estão o tamanho e o valor de mercado das empresas, fluxo de caixa e rendimentos. Os resultados mostraram que o valor de mercado e os rendimentos com o fluxo de caixa foram as variáveis que mais impactaram sobre os retornos dos ativos.

O modelo de três fatores de Fama e French (1993) foi usado por Baks, Metrick e Wachter (2001) para avaliar o desempenho mensal de 1437 fundos. Com inferência frequentista e bayesiana foram incluídas crenças a priori sobre a motivação na formação das carteiras. O objetivo foi entender o resultado da escolha dos investidores entre ativos livres de risco, fundos indexados e fundos gerenciados ativamente, para então avaliar a habilidade dos gestores. Usado como medida de performance, o alfa do modelo foi considerado uma característica dos gestores e não dos fundos. Os resultados mostraram que os retornos mais significativos se deram por meio de uma gestão cética, ou seja, menos disposta a assumir riscos. Os autores também concluíram que a maior parte dos 
investidores não possuem estratégias de negociação sofisticadas (como resultados de testes estatísticos) quando escolhem títulos de gestão ativa, sendo dirigidos por regras simples como a cobrança de taxas e impostos.

Pástor e Stambaugh (2002) mostraram que as estimativas do alfa e do índice de Sharpe, comumente usadas para avaliação de desempenho, se tornam mais precisas com o uso de retornos de ativos aparentemente não correlacionados (não usados na definição dessas medidas). Os alfas foram estimados com os modelos CAPM e três fatores de FamaFrench. A amostra contou com 2609 fundos mútuos de ações dos EUA entre os anos de 1963 e 1998. A estratégia da pesquisa consistiu em criar uma referência para o alfa de um fundo, a partir do alfa estimado para uma amostra num horizonte de tempo muito maior. Assim, essa referência aparentemente não estará correlacionada com o fundo avaliado, melhorando as estimações pelo método MQO. A metodologia proposta também mostrou precisão até cinco vezes maior no cálculo do índice de Sharpe. Os autores concluem que o modelo de precificação não é a característica mais relevante na estimativa do alfa de um fundo, que se torna mais preciso quando usados retornos de ativos fora do índice de referência, uma vez que esses retornos também incorporam informações. Vale destacar que a maioria dos fundos estudados apresentaram desempenho menor que os benchmarks nos dois modelos usados.

Friesen e Sapp (2007) verificaram que a habilidade de market timing $^{6}$ na tomada de decisão dos investidores, acaba por reduzir significativamente seus retornos médios. Isso quer dizer que o baixo desempenho do investidor ativo de pequeno porte com relação ao tempo de alocação dos seus recursos prejudica amplamente o valor adicionado pelos fundos que oferecem alfa positivo. A taxa interna de retorno e os retornos ponderados no tempo foram usados para medir respectivamente o desempenho dos investidores e dos fundos. Uma comparação entre o desempenho dos investidores em fundos de índice e fundos não indexados mostrou que em ambas as categorias, as decisões sobre o capital são tomadas no tempo errado. Esse resultado sugere que uma quantidade significativa dos investidores que seguem estratégias passivas escolhem títulos indexados que não são necessariamente passivos. Outro dado interessante da pesquisa foi a descoberta de que os investidores com habilidade para escolher fundos com melhor desempenho apresentaram

\footnotetext{
${ }^{6}$ De acordo com Fama (1970), a previsibilidade em torno do mercado financeiro está dividida em micro ( security selection) e macro (market timing). A primeira representa a habilidade de antecipar o movimento nos preços das ações individualmente, enquanto a segunda é a capacidade de prever movimentos gerais no mercado de ações.
} 
piores resultados, mostrando que perseguir o retorno pode custar caro mesmo quando se encontra um fundo com resultados promissores.

Enquanto Carhart (1997) mostrou que para o mercado norte americano, os fundos com baixo desempenho passado (Losers) têm maior tendência de reproduzi-lo no longo prazo, Huij e Post (2011) encontraram evidências de que em países emergentes, essa persistência de performance é maior entre os fundos com melhor desempenho. Os autores creditam esse resultado à menor eficiência desses mercados, que acaba por gerar maiores oportunidades para os gestores. Para essa análise, foram usados alguns modelos de fatores e dentre eles, o modelo de quatro fatores de Carhart. A amostra contou com fundos de 22 países emergentes de todo o mundo (como Brasil, China, Egito, Índia e Rússia) e a proxi usada para taxa livre de risco foi a T-Bill. Vale ressaltar que dentre os resultados, o coeficiente estimado para o fator SMB não foi estatisticamente significante.

O trabalho Jank (2012) buscou responder se os fluxos de entrada e saída de capital nos fundos estavam relacionados com notícias sobre a economia real. Por meio de variáveis como a taxa $T$-Bill, relação entre consumo-riqueza, preço-dividendos e spread de inadimplência, o autor encontrou evidências de que os fluxos no mercado de ações normalmente funcionam como uma resposta à fatores macroeconômicos, acabando por influenciar nos retornos. Corroborando com o resultado demonstrado por Fama (1990), de que os retornos do mercado de ações são uma forma de prever o futuro da atividade econômica, a afirmação de Jank explica as maiores saídas de capital dos fundos com maiores riscos diante de notícias econômicas ruins. Essa análise de fluxos nos fundos também revela aversão ao risco, demonstrando que os investidores tendem a deixar o mercado de ações em momentos de crise.

Blanco (2012) comparou a eficiência do CAPM com o modelo de três fatores de Fama-French por meio de regressão de séries temporais. Foram usados dados mensais de retorno de ações norte americanas de 1926 a 2006. As regressões foram calculadas para diferentes carteiras e os resultados comparados. Observou-se facilmente que o CAPM não apresentou evidência empírica que demonstrasse sua eficiência, resultado contrário ao do modelo de Fama-French. No entanto, o autor concluiu que os resultados para o modelo de três fatores dependem bastante da maneira como as carteiras estudadas são formadas.

Asness, Moskowitz e Pedersen (2013) aplicaram um modelo simples de três fatores que descreveu consistentemente os retornos da sua amostra, composta por ativos de 
diferentes países. A robustez dos resultados indicou a presença de riscos globais comuns. Também foi encontrada uma forte estrutura de correlação entre os retornos dos portfólios de valor e momentum, quando estes são analisados em conjunto. Os autores concluem que essa correlação observada pode ser explicada em parte pelo risco de liquidez de financiamento.

Agnesens (2013) aplicou regressões multivariadas de dois estágios nos modelos de três fatores de Fama-French e quatro fatores de Carhart, sugerindo que a grande variação nos resultados da literatura se devem à erros metodológicos. O autor ressalta que as abordagens usuais assumem implicitamente a independência da seção transversal, podendo fornecer resultados enviesados. A amostra contou com 2111 ações dos EUA entre os anos de 2002 a 2012. Os resultados evidenciaram falta de habilidade dos gestores para produzirem retornos anormais, além da tendência de os fundos manterem o desempenho passado por mais alguns meses. Não foram encontradas relações significativas entre o desempenho dos fundos e suas despesas, idade, entradas, cargas, diversificação e giro. No entanto, foi notado que fundos com despesas mais altas apresentam desempenho superior.

\subsection{Mercado de fundos no Brasil}

A primeira parte desta revisão de literatura apresentou a evolução dos modelos de avaliação de ativos, mostrando o desenvolvimento dos trabalhos até a criação dos fatores de risco utilizados nas análises dessa pesquisa. Em seguida, foram mencionados alguns dos resultados encontrados na literatura internacional, onde se pode notar que a maioria das publicações trata sobre o mercado norte americano. Esta seção faz um levantamento sobre os trabalhos brasileiros relacionados ao tema pesquisado, observando-se as diferenças entre as métricas e os resultados alcançados por eles. O objetivo dela é fundamentar as análises e obter parâmetros de comparação que considerem as especificidades do mercado brasileiro, contribuindo para uma discussão mais aprofundada dos resultados.

Franz e Figueiredo (2003) utilizaram alguns modelos teóricos derivados do CAPM para testar no mercado real brasileiro a existência da capacidade de market timing nos gestores de fundos de ações. A pesquisa utilizou dados de 454 fundos entre os anos 1995 e 2000. Os autores chamam atenção para a possibilidade dos retornos adicionais serem ocultados pela alta carga de taxas e impostos, que acabaria interferindo nos resultados. 
De acordo com a metodologia aplicada, concluiu-se que não se pode inferir a existência da habilidade de antecipação ao mercado por parte dos gestores. Os autores argumentam que essa pode ser a explicação para a existência de uma quantidade significativamente maior de fundos com gestão passiva ou não referenciados, quando comparados aos fundos de gestão ativa. No entanto, esse resultado também poderia indicar eficiência do mercado, uma vez que nesse contexto não importaria a habilidade dos administradores e os retornos anormais seriam atribuídos à sorte.

Considerando os custos adicionais gerados pela gestão ativa, Rochman e Junior (2006) analisaram quatro categorias de fundos entre 2001 e 2006, com o intuito de saber se essa realmente é uma boa opção para os investidores. O modelo usado no estudo foi o de Jensen (1968), que como citado anteriormente, adicionou o termo $\alpha$ (relacionado à habilidade dos gestores) ao CAPM. As regressões foram feitas pelo método dos Mínimos Quadrados Ordinários (MQO). Os resultados mostraram que fundos de ações e multimercados mais antigos e com maior patrimônio líquido apresentam os melhores resultados, agregando valor mesmo diante das altas taxas cobradas. Não foi possível fazer a mesma afirmação para os fundos de renda fixa por exemplo, uma vez que os valores dos alfas significativos encontrados foram diretamente proporcionais apenas ao tamanho de cada fundo.

Leusin e Brito (2008) aplicaram testes paramétricos e não paramétricos com o objetivo de identificar fatores que tiveram micro e macro contribuições na previsão do movimento nos preços das ações. A pesquisa mostrou que poucos gestores de fundos brasileiros possuem habilidade de market timing. Os autores ressaltam que essa competência está relacionada à capacidade de antecipação de alguns profissionais, que geram valor aos fundos com o retorno das ações, quando o desempenho destas supera o retorno observado nos ativos de renda fixa. O resultado corroborou com o trabalho de Brito (2003), que também concluiu pela falta de market timing entre os gestores, uma vez que poucos deles demonstram possuir habilidades empíricas para gerar excesso de retorno.

Murakoshi e Brito (2009) replicaram o trabalho de Hahn e Lee (2006) para o mercado brasileiro, com o objetivo de avaliar o impacto de cinco fatores de risco não diversificáveis sobre o retorno de 16 carteiras de investimento. Essas carteiras foram formadas de acordo com o tamanho e valor de mercado das empresas. A análise em cross-section foi feita para todos os ativos negociados na Bovespa entre os anos de 1996 
e 2005. O modelo utilizado inclui dois fatores ligados ao risco de crédito e de prazo, além dos fatores de mercado, tamanho e valor, conforme o modelo de três fatores de Fama-French. Mais uma vez os resultados mostraram que o fator de mercado sozinho não é capaz de explicar as variações dos retornos e além disso, o fator SMB não foi significativo para a amostra. Apesar de os autores concluírem pelo ganho explicativo dos modelos multifatoriais, os interceptos calculados foram significantes e diferentes de zero, evidenciando que parte dos retornos ainda não está sendo explicada pelos fatores.

Castro e Minardi (2009) investigaram se os fundos de gestão ativa no Brasil realmente entregaram retornos acima da carteira de equilíbrio de mercado e dos fundos de gestão passiva. Foram analisados dados mensais de retorno bruto (estimado) e retorno líquido de 577 fundos ativos e 49 fundos passivos de 1996 a 2006, com o modelo de quatro fatores de Carhart. Foi possível notar que os fundos com maior patrimônio líquido apresentam melhores retornos para os investidores. Os resultados também mostraram que em média, os fundos ativos apresentaram alfa negativo e significativamente diferente de zero quando usados os retornos líquidos. Com o retorno bruto notou-se uma diminuição nos fundos com alfa negativo e um aumento nos fundos com desempenho superior, além de uma diminuição nos fundos com baixo desempenho. A conclusão direta diante desse resultado é de que as taxas cobradas pelos fundos de gestão ativa destroem o valor alcançado pela habilidade dos gestores, sustentando a hipótese de desempenho equivalente entre fundos ativos e passivos.

Gomes e Cresto (2010) usaram dados diários e mensais de uma amostra com 76 fundos Long-Short ${ }^{7}$ brasileiros entre 2001 e 2008 para analisar com o CAPM, se os clientes desses fundos estavam obtendo alfa independente do retorno de mercado ou apenas comprando retornos já apresentados pelo beta. Em seguida, os autores acrescentaram mais um fator à equação para identificar a existência de market timing, observando o comportamento dos fundos e comparando-o com o restante do mercado. Não encontraram evidência de maior capacidade preditiva dos gestores, pois apesar de alguns conseguirem formar carteiras rentáveis com a escolha dos ativos, concluíram que poucos fundos foram capazes de gerar de retorno acima do mercado. O trabalho também evidenciou a dificuldade

\footnotetext{
${ }^{7}$ São fundos multimercados, que operam com oportunidades de arbitragem, fazendo uso de uma estratégia chamada de Long e Short. Com ela são comprados e vendidos títulos semelhantes, com o objetivo de que o título comprado tenha uma valorização superior ao vendido.
} 
em manter o bom desempenho por longos períodos de tempo, demonstrando que esse resultado pode não ser um fator relacionado ao timing.

Um estudo interessante de Araújo, Oliveira e Silva (2012) fez o levantamento de artigos publicados no Brasil entre 1997 e 2008, com temas relacionados ao modelo CAPM. Das 43 publicações da amostra, a maioria informou dados incompletos e quase um terço delas comparou o CAPM com outros modelos. A intenção dos autores foi conhecer os métodos e conclusões acerca dessa literatura no país. A grande maioria dos trabalhos usou dados retirados da Economática, análise em cross-section, regressão linear simples e o Ibovespa como proxi para a carteira de mercado. Os artigos que utilizaram a SELIC como taxa livre de risco concluíram que o modelo atende às necessidades propostas. No entanto, a maioria deles utilizou o CDI como taxa livre de risco e refutou a eficácia do CAPM.

Pinto (2014) aplicou o modelo CAPM e o método dos mínimos quadrados para estudar a performance de fundos brasileiros de ações, usando o alfa de Jensen como medida do desempenho. O período analisado foi entre os anos de 2000 e 2014, com o objetivo de saber se estes fundos geraram valor, e quais fatores teriam sido determinantes. Concluiu que o valor do alfa é diretamente proporcional ao tamanho e inversamente proporcional ao tempo e taxa de administração dos fundos. Além disso, cada unidade adicional de risco gera valor quando alfa é positivo e destrói valor quando alfa é negativo.

Laes e Silva (2014) analisaram o desempenho de 1111 fundos de ações brasileiros com gestão ativa, no período de 2002 a 2012, usando retornos semanais aplicados ao modelo de quatro fatores de Carhart. O objetivo foi identificar se a ocorrência de bom desempenho estava de fato associada com maior habilidade dos gestores. Os parâmetros foram encontrados com procedimento de bootstrap, mostrando que os fundos maiores tiveram melhor desempenho que os de pequeno e médio porte. Além disso, a gestão profissional não agregou valor que pudesse superar as despesas e taxas adicionais cobradas por eles. Pela análise dos alfas anualizados de cada fundo, verificou-se que alguns deles apresentaram retornos acima do esperado apenas em alguns momentos, demonstrando que esses episódios estão mais associados à sorte do que eficiência na gestão.

Filho e Sousa (2015), usaram análise multivariada para combinar alguns índices de desempenho utilizados no mercado com características dos fundos de ações. A amostra da pesquisa contou com 173 fundos analisados entre os anos de 2003 a 2010. Inicialmente os fundos divididos em dois períodos, para que um grupo fosse usado na estimação da 
regressão e o outro na validação do modelo. Em seguida, o primeiro grupo foi ordenado e dividido em quatro amostras, de acordo com o índice de Sharpe. Os extremos foram selecionados e classificados como alto e baixo desempenho. Através do retorno médio mensal retirado da Economática, do índice Bovespa, taxa Selic e CDI (Certificado de Depósito Interfinanceiro), os autores calcularam os índices de Sharpe, Treynor, Sortino, Modigliani, alfa de Jensen e information ratio. O objetivo da pesquisa foi encontrar fundos com maior probabilidade de manter um bom desempenho, além determinar quais índices estariam associados a esse resultado. A conclusão foi de que existe uma maior probabilidade de repetição dos bons resultados para fundos que cobram taxa de performance. Além disso, os resultados mostraram que as variáveis associadas à maior probabilidade de manutenção do bom desempenho são os índices de Traynor, Sharpe generalizado, Modigliani e a taxa de administração.

Para verificar se o retorno dos fundos brasileiros está associado à habilidade dos gestores ou é somente um fator de sorte, Borges e Martelanc (2015) utilizaram o modelo de quatro fatores de Carhart com a metodologia apresentada por Fama e French (2010). Foram geradas simulações bootstrap com alfa fixado em zero para se observar se esses fundos apresentariam retornos anormais persistentes, e simulações a partir de retornos reais para estudar a distribuição dos alfas. Dessa forma, se houvesse a mesma proporção de retornos acima ou abaixo da média nas duas amostras, ficaria evidenciado desempenho anormal devido à sorte. Os resultados mostraram que para o mercado de fundos de ações brasileiro existe desempenho anormal associado à habilidade dos gestores, uma vez que a proporção de fundos reais com retornos acima da média foi maior que a dos fundos com retornos simulados.

Rebeschini e Leal (2016) usaram um modelo de APT com um fator de mercado e outros quatro fatores macroeconômicos, para tentar explicar o retorno passado de fundos de investimento em ações no Brasil. A amostra contou com 73 fundos estudados entre 2002 e 2012. Os resultados mostraram ganho no poder explicativo do modelo quando comparado ao CAPM. Depois da estimação pelo método dos mínimos quadrados, o risco de mercado e a estrutura a termo da taxa de juros foram os únicos fatores que mostraram resultados consistentes. A confiança do investidor ${ }^{8}$ foi calculada como a diferença entre a taxa de empréstimos divulgada pelo Banco Central e o CDI acumulado. Assim, essa

\footnotetext{
${ }^{8}$ Burmeister, Roll e Ross (1994) introduziram o fator de risco chamado de confidence risk (CR) como a diferença entre a taxa de retorno de títulos privados, dada pelo ganho de capital mais a taxa de juros, e
} 
medida em conjunto com a inflação e a atividade econômica não apresentaram resultados com significância estatística.

Varga e Brito (2016) testaram o poder explicativo de algumas características das empresas para o retorno de ações brasileiras. Os dados mensais de 332 ativos entre os anos de 1999 e 2015 formaram um painel não balanceado para análise cross-section. Os resultados mostraram que o índice $\mathrm{BE} / \mathrm{ME}$ foi o mais significativo, principalmente nos períodos mais antigos da amostra. O fator relacionado ao momentum (medido como o retorno acumulado dos últimos 12 meses) se mostrou diretamente proporcional à liquidez dos títulos. Fatores relacionados ao mercado e tamanho das empresas não apresentaram significância estatística para explicar os retornos, quando usados em conjunto.

Nerasti e Lucinda (2016) compararam os resultados dos modelos CAPM, três fatores de Fama-French e o quatro fatores de Carhart, para analisar se os fundos brasileiros mantém o bom desempenho do ano anterior no ano seguinte. Também foi adicionado um fator de risco ligado à liquidez dos ativos no portfólio, para verificar seu papel sobre o retorno. A análise feita com 545 fundos no período de 2001 a 2014 apresentou o modelo de Carhart como o melhor para explicar os retornos. Os modelos mostraram que o fator de mercado impactou mais os fundos com os melhores e piores desempenho. O fator WML se mostrou o de maior influência sobre os resultados e a análise dos alfas não apresentou evidência de desempenho superior devido à habilidade dos gestores.

\subsection{Estrutura dos Fundos de Investimento no Brasil}

A Comissão de Valores Mobiliários (CVM) é uma autarquia ${ }^{9}$ que normatiza, fiscaliza e desenvolve o mercado de valores mobiliários no Brasil. De acordo com a entidade, os fundos brasileiros são constituídos em forma de condomínio, isso quer dizer que as cotas dos fundos são escriturais e nominativas, e os cotistas são responsáveis por eventual ocorrência de patrimônio líquido negativo. $\mathrm{O}$ valor da cota é resultado da divisão do patrimônio líquido do fundo ${ }^{10}$ pelo número de cotas emitidas, quantificadas e avaliadas no fechamento

a taxa dos T-bonds. Para os autores, CR positivo reflete um ganho de capital, o que indica aumento na confiança do investidor.

${ }^{9}$ Entidade com uma administração pública indireta, ou seja, dirigida por um Colegiado (formado por um presidente e quatro diretores) nomeado pelo Presidente da República. Criada em 1976 e sediada no Rio de Janeiro, a CVM possui personalidade jurídica própria e apesar de estar associada ao Ministério da Fazenda, não é subordinada à ele.

${ }^{10} \mathrm{O}$ patrimônio líquido de um fundo de investimento também representa seu valor de mercado. 
do mercado. Dessa forma, as cotas correspondem a frações ideais do patrimônio líquido. Os fundos abertos têm suas cotas negociadas livremente por instituições contratadas pelo administrador, já os fundos fechados têm prazo de 180 dias do seu início para registrar e encerrar a distribuição delas (INSTRUÇÃO, 555/14).

Outra importante entidade é a Associação Brasileira das Entidades dos Mercados Financeiro e de Capitais (ANBIMA), criada em 2009 a partir da fusão entre a Associação Nacional dos Bancos de Investimento (ANBID) e a Associação Nacional das Instituições do Mercado Financeiro (ANDIMA). Representando diversas instituições vinculadas ao mercado de capitais (como bancos, gestoras e corretoras), a ANBIMA possui função regulatória, certificadora e informativa, com o objetivo de buscar a internacionalização e atender às expectativas da sofisticada e crescente indústria de fundos brasileira. De acordo com a IIFA (2018), a indústria brasileira é a décima maior do mundo, com patrimônio líquido de cerca de 5 trilhões de reais (74\% do PIB), investidos principalmente no mercado doméstico ${ }^{11}$.

A partir de 2015 entrou em vigor a nova classificação de fundos da ANBIMA, considerando características utilizadas globalmente. Dentre os principais objetivos, essa recente classificação busca padronizar o mercado e criar referências que facilitem a identificação, seleção e comparação entre os tipos de fundos e outros produtos de investimento. Ela também contribui com a comunicação entre os especialistas do mercado, facilitando o processo de gestão e investimento. Essa nova classificação dos fundos apresenta três níveis hierárquicos: o primeiro se refere às classes de ativos estipuladas pela Instrução $\mathrm{n}^{\mathrm{O}}$ 555/14 da CVM, uma das quais estão os fundos de ações; o segundo faz referência ao tipo de gestão e riscos, indicando por exemplo, se o fundo procura seguir algum índice de mercado ou superar seu desempenho; e o terceiro nível mostra a estratégia usada no processo de investimento. Todos os fundos devem manter sua política de investimento e objetivos bem definidos em seu regulamento.

Pela normatização da CVM, para ser considerado um fundo de ações o fundo deve possuir pelo menos $67 \%$ da carteira investidos em ações, negociadas à vista na bolsa de valores ou outra entidade financeira do mercado de balcão organizado. De acordo com a nova classificação, os fundos que são objeto dessa pesquisa pertencem à Classe de Ações ( $1^{\circ}$ nível), com quase $78 \%$ deles na Categoria Ativos ( $2^{\circ}$ nível). Os fundos de ações Ativos

\footnotetext{
${ }^{11}$ Apenas $1 \%$ dos fundos são offshore, ou seja, constituídos no exterior, mas com investimentos também no mercado brasileiro
} 
por exemplo, são fundos que normalmente buscam superar algum índice de referência do mercado, ou apenas se baseiam neles. As definições das categorias e subcategorias ANBIMA conforme a composição da amostra deste trabalho podem ser encontradas no apêndice B. 


\section{DAdOS E MÉTODO}

O objetivo deste capítulo é apresentar brevemente a base de dados utilizada no desenvolvimento deste trabalho bem como suas fontes, os modelos econométricos e os métodos de estimação empregados para estudar o desempenho dos fundos. A adição do novo fator APB (relacionado com as estratégias de grupo na gestão ativa) ao tradicional modelo de quatro fatores de Carhart representa uma contribuição original às pesquisas sobre a indústria de fundos brasileira.

Os modelos empregados foram concebidos originalmente para pesquisa no mercado norte americano no entanto, estudos como Huij e Post (2011), Shaker e Elgiziry (2014), Mussa, Famá e Santos (2012) e Laes e Silva (2014) mostram que eles continuam válidos para análise da indústria em outros mercados menos eficientes, como é o caso do Brasil. Para esclarecer algumas adaptações necessárias ao mercado brasileiro, considerou-se necessário explicar brevemente o cálculo dos fatores de risco, mesmo que eles tenham sido disponibilizados já calculados pelo NEFIN. O período escolhido para este estudo foi de janeiro de 2009 a dezembro de 2017. O motivo desta opção foi porque procurou-se evitar dados (antes e após esse intervalo de tempo) que devido à períodos de instabilidade econômica ou política, pudessem enviesar as análises. Como poucos fundos estavam em operação durante todo esse intervalo de tempo, o painel final é não-balanceado. Conforme Fama e French (1993) e Carhart (1997), a análise foi feita em cross-section pelo método dos Mínimos Quadrados Ordinários (MQO) com efeito fixo.

A seção 3.1 apresenta o painel utilizado, descrevendo brevemente as fontes e os critérios escolhidos para a seleção e tratamento dos dados. São apresentados os fatores de risco do modelo e as categorias dos fundos analisados, classificados pela ANBIMA de acordo com seu objetivo e estratégia de investimento (que seguem critérios da CVM). Essas categorias foram utilizadas neste trabalho para dividir os fundos para análise por grupos semelhantes. Na seção 3.2 é mostrado o cálculo das variáveis explicativas e a construção dos modelos, além do método empregado para o cálculo dos coeficientes. 


\subsection{Descrição dos Dados}

O objetivo dessa seção é mostrar os dados utilizados neste trabalho. Os retornos mensais em moeda corrente ajustados pela inflação, categoria e subcategoria ANBIMA, patrimônio líquido, despesas anuais, taxas e regulamento dos fundos ${ }^{1}$ foram obtidos da base de dados da Economática. Para o cálculo do fator APB as estimações usam o retorno bruto, ou seja, o retorno divulgado pelo fundo (que é líquido das despesas) somado às taxas cobradas por eles. Para efeito de comparação, foram feitas estimações em que a variável dependente (excesso de retorno) é o retorno líquido menos $R_{f}$ e o retorno bruto menos $R_{f}$. O uso do retorno bruto tem por objetivo direcionar as análises para o resultado alcançado pelos fundos, sem considerar as possíveis desvantagens nos custos do gerenciamento ativo de uma carteira, conforme alerta Carhart (1997). Laes e Silva (2014) explicam que a literatura comumente faz uso do retorno líquido nos modelos de avaliação para concentrar a análise no desempenho alcançado pelos investidores e não na performance dos gestores, uma vez que as despesas são basicamente devido aos custos de transação. Além disso, muitos fundos informam as taxas máximas cobradas, impossibilitando a formação de uma série histórica para o cálculo mais preciso do retorno bruto.

Periodicamente são lançados novos fundos são pelas gestoras, permanecendo abertos apenas os que se mostram mais atrativos para os investidores. Esse período de teste em que um fundo recém aberto ainda tem grandes chances de ser encerrado (chamado de incubação), foi bem documentado por Carhart (1995), Wermers (1997) e Brown et al. (1992). Para que esse importante processo não interfira nos resultados, muitos autores como Carhart (1997), Laes e Silva (2014), Borges e Martelanc (2015) usam critério de tempo para a seleção da amostra. Carhart (1997b) mostrou que os fundos não sobreviventes desse período são expostos a maiores riscos e acabam apresentando predominantemente baixa performance por anos seguidos, indicando que esses fundos constituem um agrupamento com características específicas. Assim, para manter uma quantidade mínima de observações nas estimações além de evitar o viés de incubação, foram retirados deste estudo os fundos com menos de 30 meses consecutivos de histórico dos retornos. Por possuir características muito específicas, também foram retirados da amostra os fundos da subcategoria monoação (categoria específicos). A amostra final da parte I é formada por 1268 fundos brasileiros

\footnotetext{
${ }^{1}$ Utilizados apenas para consulta.
} 
de ações que estavam em atividade em dezembro de 2017, totalizando 97.965 observações fundos-ano, entre os anos de 2009 a 2017.

Os fatores de risco de mercado, tamanho, valor e momento são calculados e disponibilizados pelo NEFIN $^{2}$ diariamente. O grupo utiliza metodologia análoga à de Fama e French (1993) e Carhart (1997), fazendo algumas adaptações ao mercado brasileiro, conforme será demonstrado na seção 3.2. Para compor o painel, os dados diários também foram convertidos em mensais.

O primeiro fator de risco, chamado $R M R F$, representa uma remuneração pela exposição ao risco do mercado, tido como não diversificável. Esse retorno mínimo esperado vem da junção de dois elementos: a recompensa pelo tempo que o recurso é investido (baseado na taxa de um investimento livre de risco) e a recompensa pelo risco assumido, representada por uma carteira com todos os ativos do mercado (representada no Brasil pelos ativos negociados na BOVESPA). Se este fator apresentar um valor positivo, quer dizer que o mercado está com desempenho melhor que a taxa CDI. Já o coeficiente estimado nesse fator, mostra a relação entre a carteira do fundo e a influência do mercado sobre ela. Em outras palavras, se o coeficiente for igual a 1 quer dizer que o investimento está exposto ao mesmo risco que a carteira de mercado e consequentemente, alcançando o mesmo retorno oferecido por ela. Coeficiente maior do que 1 aponta para um investimento com variação de risco e recompensa acima do mercado, enquanto um coeficiente menor do que 1 mostra que o risco assumido é menor que o risco do mercado, e consequentemente a remuneração esperada com este fator também é menor.

O segundo fator do modelo (SMB) classifica as empresas pelo seu valor de mercado, usando a mesma ponderação de índice BE/ME. É conhecido como um fator de tamanho, pois as maiores empresas, que possuem elevado volume de negociação na bolsa e consequente maior liquidez (com ações chamadas de Blue Chips) também possuem o valor de mercado mais elevado. Estabelecendo uma relação entre a diferença de performance das empresas de baixa e alta capitalização de mercado, de acordo com estudo empírico de Fama e French (1992), era esperado que este fator fosse positivo pois no curto prazo, empresas com baixa capitalização (Small) tendem a oferecer maior risco e consequentemente, maiores oportunidades de retorno do que as empresas maiores.

\footnotetext{
${ }^{2}$ O NEFIN foi desenvolvido por pesquisadores do Departamento de Economia da Faculdade de Economia, Administração e Contabilidade da Universidade de São Paulo. Tem se tornado referência para pesquisas sobre economia financeira no Brasil, fornecendo dados, relatórios, variáveis e indicadores calculados todos os dias desde 2001. Acesso pela página: www.nefin.com.br
} 
O fator HML trata da diferença de desempenho entre empresas com alto e baixo índice book-to-market (BE/ME). Conhecido como fator de valor, uma vez que papéis com alto BE/ME são considerados "ações de valor", pois costumam apresentar retornos superiores no longo prazo (FAMA; FRENCH, 1992). Ativos de empresas com baixo índice, por sua vez, são chamadas de "ações de crescimento", revelando empresas bem avaliadas pelo mercado, que apresentam perspectiva de crescimento. Assim, se um fundo tem objetivo de investimento voltado para ações de empresas de valor é esperado que o módulo do coeficiente de HML na regressão seja mais elevado, pois sua exposição à este fator de risco é maior.

O quarto fator de risco de Carhart (1997), chamado WML, simula o efeito momentum documentado por Jegadeesh e Titman (1993). De acordo com os autores, ele pode ser entendido como uma tendência no preço de uma ação continuar subindo quando está já está em alta e caindo quando já está em baixa. O coeficiente calculado para este fator mostra a exposição do fundo ao momentum, ou seja, o quanto a estratégia de uma carteira que compra títulos Winners e vende os Loosers explica o retorno alcançado. Carhart mostrou que os fundos que seguem a estratégia de momento podem ter retornos consistentemente acima da média, mas esse retorno anormal acaba consumido pelas despesas e taxas de gestão.

O fator APB foi proposto por Hunter et al. (2014) para captar o ruído idiossincrático comum entre os fundos do mesmo agrupamento, melhorando as estimações dos alfas no modelo de Carhart. Construído com o retorno médio da categoria, o fator representa um prêmio alcançado por estratégias comuns de um grupo de pares, que estaria no termo de erro dos modelos tradicionais. Uma vez que este erro possui distribuição normal com média zero, o fator APB não altera o valor dos parâmetros estimados. Apesar de os autores mostrarem em sua pesquisa que o fator realmente capta uma parcela do retorno não explicada pelas outras variáveis, os alfas do modelo com o fator APB se apresentaram insignificantes em longos períodos de tempo. Sua adição para análise do desempenho dos fundos neste trabalho tem por objetivo aplicar a metodologia proposta ao mercado brasileiro, observando-se as alterações na significância dos parâmetros estimados. Para separar a parte do alfa devida ao movimento comum dos gestores na formação das carteiras, os fundos foram divididos por categoria ANBIMA. O motivo desse agrupamento foi em 
razão do número de observações, que ficaria muito pequeno em algumas subcategorias, caso a amostra fosse dividida desta forma.

A construção das variáveis do modelo, seguindo procedimento semelhante ao de Fama e French (1993), Carhart (1997) e Hunter et al. (2014), o método de estimação e teste de significância dos parâmetros foram detalhados na seção 3.2. O comportamento taxa CDI no período (usada como taxa livre de risco), pode ser observado no gráfico 5 do apêndice A. Ele mostra um aumento substancial no valor da taxa entre os anos de 2013 a 2016, período em que a captação líquida da indústria de fundos foi drasticamente reduzida.

\subsection{Metodologia e tratamento dos dados}

A análise do desempenho está dividida em duas partes neste trabalho. A primeira parte segue procedimento de Carhart (1997), com um modelo que atribui o desempenho dos fundos a quatro estratégias de investimento: ações com alto e baixo beta de mercado, alta e baixa capitalização, alto e baixo índice BE/ME e ações com alto e baixo desempenho no ano anterior. Os coeficientes estimados e os prêmios nas carteiras que imitam fatores de risco indicam a proporção dos retornos atribuída a cada uma delas. Assim, o modelo proposto é consistente com a hipótese de equilíbrio de mercado, capturando a estratégia de momento documentada por Chan, Jegadeesh e Lakonishok (1996) como uma anomalia de ineficiência do mercado. Apenas para efeito de comparação, também foram estimados os parâmetros com o modelo CAPM e o modelo de três fatores de Fama e French (1993).

Foi aplicado sobre os dados o método Winsorized de $1 \%$ para eliminar valores extremos (outliers), que interferem no cálculo da média e do desvio padrão. As estimações dos dados em painel para os quatro modelos foram feitas em cross-section pelo método dos mínimos quadrados ordinários (MQO) com efeito fixo (uma vez que a habilidade dos gestores é considerada uma característica específica de cada fundo e por esse motivo, ela não varia com o tempo), conforme Carhart (1997) e Hunter et al. (2014). Esperou-se dessa forma aumentar a quantidade de estimadores within significativos, produzidos pelo efeito fixo.

A parte II deste trabalho concentra-se no coeficiente alfa do modelo, entendido como uma medida da habilidade dos gestores. O número de observações utilizadas nas 
regressões é menor do que na parte I porque foram excluídos da amostra os fundos que não apresentavam informações sobre as despesas cobradas na base de dados da Economática, de onde foram retiradas algumas das informações necessárias nessa pesquisa. Para as estimações desta seção, também foram utilizados apenas fundos com mais de 30 meses de negociação consecutiva no período de 2009-2017. O modelo escolhido foi o de quatro fatores de Carhart aumentado com o fator do APB (que representa um benchmarck para capturar o retorno associado às estratégias comuns), conforme proposto por Hunter et al. (2014). Considerando que as categorias ANBIMA são uma forma de separar os fundos por tipo de gestão e risco, elas foram o agrupamento escolhido para as análises. Espera-se que assim como no trabalho de Hunter, a adição do fator APB melhore a significância dos parâmetros, contribuindo para uma melhor avaliação da gestão.

\subsubsection{Modelo de Quatro Fatores de Carhart}

O fator de momento adicionado por Carhart ao modelo de Fama-French procura explicar o retorno dos fundos, considerando a compra de ações que tiveram altos retornos nos últimos meses e a venda de ações que tiveram baixos retornos. Portanto, esse fator revela se os fundos estudados conseguem obter rendimento através da estratégia de compra de títulos com desempenho passado acima da média. O modelo econométrico utilizado para isso foi o proposto por Carhart (1997) conforme equação (6). A variável dependente é o excesso de retorno (Ret), composta pelo retorno do fundo dado por $R_{i t}$, menos $R_{f t}$. O valor do CDI foi usado como taxa livre de risco.

$$
R_{i t}-R_{f t}=\alpha_{i t}+\beta_{1 i t} R M R F_{t}+\beta_{2 i t} S M B_{t}+\beta_{3 i t} H M L_{t}+\beta_{4 i t} W M L_{t}+\epsilon_{i t}
$$

Os valores usados para $R_{f}$ e os fatores de risco RMRF, SMB, HML e WML foram extraídos do site do NEFIN, onde são calculados de forma análoga ao procedimento adotado por Fama-French e Carhart, com algumas adaptações ao mercado brasileiro ${ }^{3}$. O primeiro fator do modelo, que corresponde ao prêmio pelo risco do mercado $(R M R F)$ é calculado pela diferença entre o retorno do mercado, tido como o valor ponderado dos retornos de todas as ações elegíveis negociadas na Bovespa menos o CDI. No cálculo do

\footnotetext{
${ }^{3}$ Disponível em http://nefin.com.br/Metodologia/Methodology.pdf
} 
segundo fator, as empresas são ordenadas de acordo com sua capitalização de mercado, tomada em dezembro do ano $t-1$. Em seguida elas são divididas em três carteiras, sendo o grupo da extremidade inferior chamado de Small e o da extremidade superior chamado de Big. O retorno ponderado $R_{t}$ da carteira Small menos o retorno ponderado da carteira Big formam o SMB. No terceiro fator de risco a ordenação é feita pelo índice book-to-market, calculado em junho do ano anterior. Três grupos são formados novamente, e o fator HML é dado pelo retorno ponderado da carteira High menos da carteira Low.

O quarto fator de risco, chamado de WML, corresponde ao retorno ponderado da carteira Winners menos a Losers. Para ele, as ações são ordenadas mensalmente de acordo com os retornos acumulados nos dez meses anteriores e divididas em três carteiras. A carteira com retornos mais altos é chamada de Winners e a carteira com retornos mais baixos chamada de Losers. O retorno médio de cada uma das carteiras usadas nos quatro fatores de risco é a somatória dos retornos individuais de cada ativo $\left(r_{t}^{i}\right)$, dividida pelo número $N$ de ativos da carteira, conforme equação (7).

$$
R_{t}=\frac{1}{N} \sum_{i} r_{t}^{i}
$$

Já o retorno de um único ativo $\left(r_{t}^{i}\right)$ no período $t$ é dado pelo preço de fechamento dessa ação (dado por $P$ ) no dia $t$, dividido pelo seu valor de fechamento no dia anterior $(t-1)$ menos um (conforme equação 8 ). Os valores usados em $P$ são ajustados por dividendos.

$$
r_{t}^{i}=\frac{P_{t}^{i}}{P_{t-1}^{i}}-1
$$

Para a linha de análise apresentada neste trabalho a literatura comumente faz uso de dados mensais para fatores de risco e retornos. O motivo para isso é manter um equilíbrio entre a perda de observações decorrente de longos intervalos de tempo, e a influência de micro aspectos do mercado que se tornam mais marcantes com intervalos pequenos. Como os fatores de risco fornecidos pelo NEFIN são diários, foi necessário 
convertê-los em mensais $\left(F_{m}\right)$ pela a equação $(9)$, na qual $F_{d}$ é o valor do fator em cada dia $d$ do mês.

$$
F_{m}=\left(\prod_{d \in d i a}\left(F_{d}+1\right)-1\right) 100
$$

\subsubsection{Modelo de Carhart aumentado com fator APB}

Para a construção do novo fator adicionado foram usadas as taxas de administração cobradas pela gestão dos fundos. Como a base de dados da Economática disponibiliza esses valores em porcentagem ao ano, foi preciso convertê-los em mensais seguindo a equação (10).

$$
T=\left(\frac{T_{\text {anual }}}{100}+1\right)^{\frac{1}{12}}-1
$$

Conforme o procedimento adotado por Hunter et al. (2014) calculou-se como demonstrado na equação (11), o retorno bruto mensal para cada fundo $\left(r_{i, t}\right)$, definido como a soma entre o valor da taxa de administração $\left(T_{i, t}\right)$ e o excesso de retorno. Esse retorno bruto foi usado como variável dependente nas regressões para concentrar a análise na habilidade dos gestores, não considerando a questão sobre a eficiência dos custos dos fundos.

$$
r_{i, t}=\left(R_{i, t}-R_{f, t}\right)+T_{i, t}
$$

Com o objetivo de formar uma referência dentro de cada agrupamento, foi calculado na equação (12) o retorno bruto de cada categoria $j$, sendo este a média de retorno de todos os fundos presentes em cada uma delas. A variável é denotada por $r_{A P B_{j, t}}$, em que $N_{A P B}$ é o número de observações em cada categoria no tempo $t$.

$$
r_{A P B_{j, t}}=\frac{1}{N_{A P B_{j, t}}} \sum_{i=1}^{N_{A P B_{j, t}}} r_{i, t}
$$


Para formar o novo fator do APB, o retorno bruto da categoria foi chamado de Ret - bruto e usado como variável dependente no modelo de Carhart (equação 13). As regressões foram estimadas dessa forma para cada categoria ANBIMA.

$r_{A P B_{j, t}}=\alpha_{A P B_{j}}+\beta_{1_{A P B_{j}}} R M R F_{t}+\beta_{2_{A P B_{j}}} S M B_{t}+\beta_{3_{A P B_{j}}} H M L_{t}+\beta_{4_{A P B_{j}}} W M L_{t}+\varepsilon_{A P B_{j, t}}$

Os resíduos mensais da regressão estimada acima foram usados como um fator comum entre as categorias, expandindo o modelo de quatro fatores de Carhart. Por esse motivo, foram chamados de $A P B_{j, t}\left(A P B_{j, t}=\varepsilon_{A P B_{j, t}}\right)$, conforme exibido na equação (14). Esse novo modelo ajuda a controlar características comuns dos fundos contidos na mesma categoria captando assim, os riscos idiossincráticos assumidos por eles. A comprovação desse resultado foi bem documentada pelos autores, mostrando que o modelo aumenta a quantidade de alfas estimados significativos do modelo de Carhart descrito na equação 6, diminuindo o termo de erro sem alterar os parâmetros dos fatores.

$$
r_{i, t}=a_{i}+\beta_{1, i}\left(R M R F_{t}\right)+\beta_{2, i} S M B_{t}+\beta_{3, i} H M L_{t}+\beta_{4, i} W M L_{t}+\lambda_{i} A P B_{j, t}+\varepsilon_{i, t}
$$

Conforme sugerido por Hunter et al. (2014), também foi aplicada uma versão do modelo com alfa-ajustado (equação 15), em que $A P B_{j, t}^{a j}=\alpha_{A P B_{j}}+\varepsilon_{A P B_{j, t}}$. Por representarem a sensibilidade dos fundos às estratégias da categoria, se os coeficientes estimados para o fator do APB nas equações (14) e (15) forem iguais a zero $\left(\lambda_{i}=\gamma_{i}=0\right)$, tem-se que o desempenho desses fundos vem de habilidades únicas de cada gestor e não está correlacionado com as habilidades médias do grupo. Se $a_{i}^{a j}=0$, então a fonte do desempenho dos fundos vem inteiramente dos efeitos do movimento em conjunto do grupo $\left(\gamma_{i} \alpha_{A P B_{j}}\right)$. Essas análises não serão feitas neste trabalho, uma vez que o intuito foi apenas observar se houve aumento de parâmetro significativos com o uso do novo fator.

$$
r_{i, t}=a_{i}^{a j}+\beta_{1, i}\left(R M R F_{t}\right)+\beta_{2, i} S M B_{t}+\beta_{3, i} H M L_{t}+\beta_{4, i} W M L_{t}+\gamma_{i} A P B_{j, t}^{a j}+\varepsilon_{i, t}
$$


Se no entanto, um subgrupo de um desses grupos usar uma estratégia diferente e superar o desempenho da categoria (os resíduos do modelo para esse subgrupo não estão correlacionados com os resíduos dos outros fundos da categoria), no modelo das equações (14) e (15), será observado $a_{i}^{a j}$ diferente de $a_{i}$ (ambos significativos) na proporção desses fundos com desempenho superior. Dessa forma, espera-se que o modelo com alfa ajustado revele a parte do retorno que vem apenas de estratégias de grupo (quando $a_{i}^{a j}=0$ ). 


\section{RESULTADOS E DISCUSSÃO}

A seção 4.1 deste capítulo apresenta as estatísticas descritivas das variáveis mensais. O objetivo é descrever algumas características da amostra e suas possíveis interpretações. Na seção 4.2 são mostrados os resultados das estimações para toda a amostra e por categoria ANBIMA. Para efeito de comparação foram usados os modelos CAPM, três fatores de Fama-French e quatro fatores de Carhart. Na segunda parte da análise são estimados os coeficientes alfa dos fundos seguindo procedimento de Hunter et al. (2014). O objetivo dessa metodologia é adicionar um fator para captar estratégias de investimento semelhantes entre fundos de mesma categoria, diminuindo a correlação entre os termos de erro e melhorando a significância na estimação dos parâmetros usados para análise de habilidade dos gestores. São apresentados gráficos e tabelas para facilitar a compreensão dos resultados e suas possíveis implicações.

\subsection{Estatística Descritiva: Variáveis dos Modelos}

De acordo com livro da CVM (2017), até 2008 a capitalização do mercado da Bovespa chegou a 93,6\%, caindo para 32,2\% entre os anos de 2009 a 2015. Apesar disso, a publicação afirma que a bolsa brasileira teve desempenho melhor que outros mercados no ano 2009, justificado pelas mesmas condições observadas nos anos anteriores que levaram ao seu crescimento como por exemplo, a volta da liquidez. O gráfico da Figura 3 representa as médias anuais (em porcentagem) do retorno em excesso (retorno líquido menos a taxa risck free) dos fundos por categoria ANBIMA.

Nota-se em 2009 uma acentuada queda nos retornos de todos os fundos (nesse período a taxa CDI também sofreu uma leve diminuição). É possível observar menores amplitudes de oscilação do desempenho médio para a maior parte dos fundos, sugerindo

uma retomada da economia. É possível notar que apenas nos anos de 2011 e 2015 houve crescimento no retorno de todas as categorias, que até o final do ano de 2017 não recuperaram os rendimentos médios do início de 2009. Com excessão apenas dos fundos específicos, que além de apresentar comportamento bem divergente das outras categorias de 2013 a 2017, obteve os maiores retornos em 2016, após grandes períodos de queda. 
Figura 3 - Excesso de retorno médio anual dos fundos por categoria ANBIMA

Os valores estão em porcentagem e se referem às médias anuais do retorno dos fundos da amostra (retirados da Economática), menos a taxa CDI (disponibilizada como Risck-free pelo NEFIN).

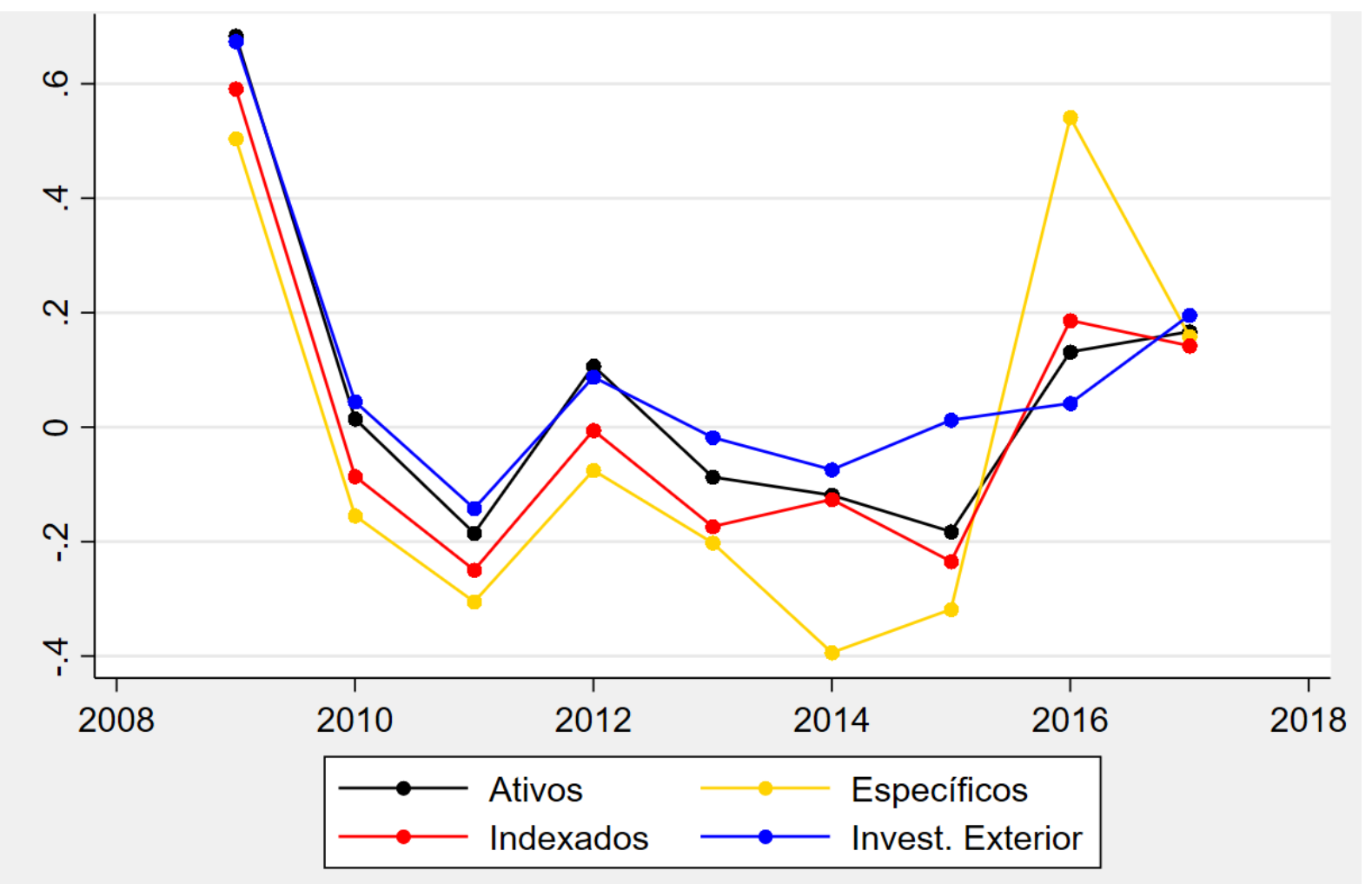

Fonte: Elaboração própria.

A Tabela 1 apresenta os valores médios calculados utilizados nas estimações, separados pelo total da amostra e por categoria ANBIMA. Eles se referem ao Ret-Bruto $\left(r_{i, t}\right)$, usado na estimação do modelo com fator $\mathrm{ABP}$, o Ret $\left(R_{i, t}-R_{f, t}\right)$, que é a variável dependente dos modelos de precificação de ativos, e os fatores de risco, que são os retornos ponderados que simulam as carteiras de mercado (RMRF), tamanho (SMB), valor (HML) e momento (WML), usadas como variáveis explicativas nas estimações. Nota-se que quase $78 \%$ das observações são de fundos pertencentes à categoria Ativos, pois essa categoria também tem o maior número de subcategorias e consequentemente, de fundos em atividade.

Uma característica do mercado de ações é a alta volatilidade, o que pode ser notado pelos altos valores encontrados no desvio padrão dos retornos em todas as categorias dos fundos de ações estudados. Pode-se facilmente notar pelo gráfico da Figura 3 e pelos resultados da tabela 1 que os fundos específicos sofreram as maiores variações de rendimento, com desvio padrão médio de $11,25 \%$, a categoria também teve o menor retorno, 
Tabela 1 - Estatística Descritiva das Variáveis Usadas nos Modelos de Performance: de Janeiro de 2009 a Dezembro de 2017

Foram extraídos da Economática os retornos (Ret) apresentados pelos fundos e as taxas e despesas cobradas por eles, que somados resultam no valor do Ret-Bruto. RMRF, SMB, HML, WML são os fatores do modelo de Carhart que imitam carteiras para o mercado, tamanho, valor e momento, todos fornecidos pelo NEFIN. Os valores da tabela são médios, uma vez que os dados utilizados nas estimações foram mensais. Apesar de os fatores de risco do modelo serem sistemáticos, eles variam por categoria na tabela porque os fundos de cada uma delas estiveram em funcionamento por períodos diferentes. $N$ representa a quantidade de observações para todos os fundos e por categoria.

\begin{tabular}{|c|c|c|c|c|}
\hline Total & Méd(\%) & Desv. Pad.(\%) & Mín(\%) & Máx(\%) \\
\hline Ret-Bruto & 0.37 & 7.41 & -99.92 & 572.04 \\
\hline Ret & 0.11 & 6.65 & -100.00 & 572.04 \\
\hline RMRF & 0.11 & 5.19 & -11.50 & 14.85 \\
\hline SMB & -0.23 & 4.67 & -10.72 & 18.53 \\
\hline HML & -0.16 & 5.00 & -10.37 & 17.50 \\
\hline WML & 1.31 & 6.20 & -23.93 & 18.63 \\
\hline$N$ & 97,965 & & & \\
\hline \multicolumn{5}{|c|}{ Fundos de Ações: Ativos } \\
\hline Ret-Bruto & 0.45 & 6.67 & -83.03 & 246.68 \\
\hline Ret & 0.13 & 5.55 & -83.15 & 246.67 \\
\hline RMRF & 0.09 & 5.19 & -11.50 & 14.85 \\
\hline SMB & -0.26 & 4.66 & -10.72 & 18.53 \\
\hline HML & -0.16 & 5.01 & -10.37 & 17.50 \\
\hline WML & 1.33 & 6.19 & -23.93 & 18.63 \\
\hline$N$ & 76,258 & & & \\
\hline \multicolumn{5}{|c|}{ Fundos de Ações: Específicos } \\
\hline Ret-Bruto & -0.09 & 11.25 & -73.01 & 116.57 \\
\hline Ret & -0.20 & 11.25 & -73.01 & 116.56 \\
\hline RMRF & 0.22 & 5.13 & -11.50 & 14.85 \\
\hline SMB & 0.06 & 4.70 & -10.72 & 18.53 \\
\hline HML & -0.26 & 4.66 & -10.37 & 17.50 \\
\hline WML & 1.12 & 6.15 & -23.93 & 18.63 \\
\hline$N$ & 9,335 & & & \\
\hline \multicolumn{5}{|c|}{ Fundos de Ações: Indexados } \\
\hline Ret-Bruto & 0.00 & 5.80 & -27.39 & 43.71 \\
\hline Ret & -0.10 & 5.80 & -27.72 & 43.38 \\
\hline RMRF & 0.16 & 5.14 & -11.50 & 14.85 \\
\hline SMB & -0.12 & 4.67 & -10.72 & 18.53 \\
\hline HML & -0.22 & 4.80 & -10.37 & 17.50 \\
\hline WML & 1.23 & 6.13 & -23.93 & 18.63 \\
\hline$N$ & 4,298 & & & \\
\hline \multicolumn{5}{|c|}{ Fundos de Ações: Invest. no Exterior } \\
\hline Ret-Bruto & 0.40 & 8.97 & -99.92 & 572.04 \\
\hline Ret & 0.34 & 8.97 & -100.0 & 572.04 \\
\hline RMRF & 0.08 & 5.27 & -11.50 & 14.85 \\
\hline SMB & -0.34 & 4.69 & -10.72 & 18.53 \\
\hline HML & -0.02 & 5.30 & -10.37 & 17.50 \\
\hline WML & 1.37 & 6.35 & -23.93 & 18.63 \\
\hline$N$ & 8,074 & & & \\
\hline
\end{tabular}


ficando $0,2 \%$ abaixo do CDI. Os fundos indexados também tiveram desempenho médio alcançado abaixo da taxa livre de risco, que pode ser observado pelas médias negativas nos retornos entre 2010 e 2015. A partir de 2016 houve nova queda no valor do CDI, período em que os fundos Indexados e Específicos apresentaram nova queda no desempenho.

O Ret - Bruto corresponde à soma das taxas cobradas com o excesso de retorno (que é líquido das despesas) apresentado pelos fundos e por esse motivo, sua magnitude é sempre maior que o valor do Ret (excesso de retorno). A diferença entre o valor do retorno e do retorno bruto revela que os fundos Ativos cobram as taxas mais altas, enquanto os fundos Invest. no Exterior cobram as menores taxas. Esse resultado era de esperar, uma vez que o custo de gerenciamento de uma carteira com estratégia de investimento ativa é de fato mais elevado. Em contrapartida, fundos que investem a maior parte do seu PL no exterior podem encontrar oportunidades com melhores taxas. Além disso, as duas categorias também apresentaram os maiores retornos médios no período.

Cada fator de risco é sistemático e constitui um único valor mensal para toda a amostra. No entanto, os fundos presentes na base de dados operaram por períodos diferentes. Alguns deles estiveram abertos por todo o período de tempo analisado enquanto outros estão pouco acima do corte de 30 meses de histórico de retorno. Por esse motivo, a tabela apresenta valores médios diferentes para RMRF, SMB, HML e WML em cada categoria, que correspondem aos retornos médios das carteiras que cada um deles representa, no período específico de tempo que os fundos de determinada categoria estiveram presentes. As médias positivas para RMRF mostra que nos anos analisados, o mercado de ações superou em média $0,11 \%$ os rendimentos obtidos com uma carteira vinculada ao CDI. O resultado é bem diferente do encontrado por Murakoshi e Brito (2009) para o prêmio do mercado Bovespa de 1995 a 2005. Os autores calcularam -0,23\% para RMRF, ressaltando que provavelmente o valor negativo seja devido às altas nas taxas básicas de juros da economia no período, tornando difícil o retorno da bolsa ser superior a este. Para o mercado norte americano, Carhart (1997) encontrou prêmio de 0,47\% para essa proxi.

De acordo com resultados de Fama e French (1993), eram esperados prêmios positivos para as carteiras de SMB e HML. No entanto, os valores encontrados foram negativos para quase todas as categorias, confirmando resultado encontrado por Braga e Leal (2000), Málaga e Securato (2004) e Roschel (2020), que não encontraram evidência de que em média as empresas brasileiras com baixa capitalização de mercado performam 
melhor. A conclusão direta que se pode chegar a partir do retorno médio da carteira de tamanho é que investir em Small Caps foi menos rentável para os fundos no período, exceto para a categoria Específicos. Os fundos dessa categoria estiveram expostos a um fator de risco SMB positivo, resultado de um período em que as o retorno das ações Small foi superior, performando de forma semelhante ao padrão norte americano documentado por Fama e French (1993) e Carhart (1997). No entanto, esse resultado não sugere ter sido essa a estratégia adotada por essa categoria, uma vez que ela pode ser verificada apenas diante do coeficiente da regressão. Murakoshi e Brito (2009) explicam que o baixo retorno das Small Caps encontrado também pode ser resultado de maiores custos e acesso ao capital, além da carga tributária e complexidade fiscal do país, fazendo-as competir de forma desigual com empresas informais, demonstrando uma queda no valor desses ativos diante da expectativa do mercado.

Na análise de Carhart (1997) para ativos dos Estados Unidos, os valores médios encontrados para todos os fatores de risco foram positivos, evidenciando uma diferença no comportamento com relação aos ativos brasileiros. Eles revelam que em geral no Brasil, papéis de empresas maiores (com alta capitalização de mercado, as chamadas Blue Chips) e empresas com perspectiva de crescimento (baixo índice BE/ME) alcançaram retornos superiores no período de 2009 a 2017. Fama e French (1993) ressaltam que baixo índice BE/ME (book-to-market) pode acontecer em decorrência de altos investimentos apresentados nos relatórios contábeis, que ocasionam um aumento na cotação dos ativos da empresa e consequente diminuição do índice, ou ser um reflexo de baixo valor de mercado ocasionado por baixos valores contábeis. Carhart também menciona que a magnitude dos fatores das carteiras de tamanho, valor e momento (tal como apresentada na tabela) sugere que esses fatores são responsáveis por grande parte da variação transversal dos retornos, uma vez que representa a diferença de retorno nas estratégias de investimento de diferentes carteiras.

Uma vez que WML é construído com a diferença entre o retorno das ações com melhor e pior desempenho passado, o valor do fator é positivo para toda a amostra. Além disso, é o fator que apresenta maior magnitude, mostrando que a estratégia de momento é a que explica a maior parte da variação transversal média dos retornos dos fundos. No entanto, apesar da pequena variação, ela foi menor para os fundos Específicos e maior para 
os Invest. no Exterior. É importante ressaltar que os fatores são sistemáticos e portanto, possuem os mesmos valores para todos os fundos quando analisados no mesmo período.

A tabela 2 apresenta a matriz de correlação dos fatores de risco. Gujarati e Porter (2011) explicam que a depender da significância, correlação alta (maior do que 0,8) indica presença de multicolinearidade. Ou seja, revela a existência de uma relação linear entre as variáveis explicativas, dificultando a estimação de parâmetros mais precisos (com erros padrão pequenos). Esse problema pode ocorrer em razão do método empregado na coleta de dados, além da escolha de um modelo mais restrito e mal especificado (as variáveis explicativas não são as mais apropriadas). Apesar disso, os autores esclarecem que as estimativas na presença de multicolinearidade continuam consistentes e não viesadas. Acredita-se que esses problemas não estejam presentes nas estimações deste trabalho, uma vez que além de o modelo e os métodos empregados serem bastante documentados e aceitos pela literatura, as estatísticas de teste das regressões foram bastante significantes. Apesar de os valores da tabela não serem tão baixos como os exibidos por Carhart $(1997)^{1}$, eles não são altos e se apresentam similares aos encontrados por Laes e Silva (2014) para o Brasil.

Tabela 2 - Correlação entre os fatores de risco do modelo de Carhart

\begin{tabular}{|c|c|c|c|c|}
\hline & \multicolumn{4}{|c|}{ Correlação } \\
\hline Fator & RMRF & SMB & HML & WML \\
\hline$\overline{\mathrm{RMRF}}$ & 1 & & & \\
\hline SMB & $0.3733^{*}$ & 1 & & \\
\hline HML & $0.5180^{*}$ & $0.5401^{*}$ & 1 & \\
\hline WML & $-0.4902^{*}$ & $-0.5942^{*}$ & $-0.4557^{*}$ & 1 \\
\hline
\end{tabular}

A significância estatística de $10 \%, 5 \%$ e $1 \%$ está indicada por ${ }^{*},{ }^{* *} \mathrm{e}^{* *} *$, respectivamente.

Pode ser verificado que o fator SMB possui a menor e maior magnitude de correlação da tabela com relação a RMRF e WML respectivamente. Valores médios negativos representam comportamentos contrários nas características correlacionadas, como observado entre o WML e os outros fatores. Os valores médios totais da tabela 1 corroboram com esse argumento, uma vez que os prêmios de SMB e HML foram negativos, enquanto

\footnotetext{
${ }^{1}$ Carhart menciona que a alta variância dos fatores associada com baixa correlação entre eles sugere que o modelo de quatro fatores pode explicar as variações temporais dos retornos.
} 
WML foi positivo. Apesar do RMRF também apresentar retorno positivo, ele foi bem menor que o fator de momento.

\subsection{Resultados das Estimações}

As próximas subseções mostram os resultados e a discussão em torno dos parâmetros encontrados nas regressões e dos alfas estimados com o fator APB. A primeira parte da análise apresenta as estimações com modelo CAPM, três fatores de Fama-French e quatro fatores de Carhart. São discutidas as implicações práticas, além dos testes de ajuste e comparação entre os resultados para toda a amostra e por categoria ANBIMA. Na segunda parte são discutidos os resultados com o uso do modelo de Carhart aumentado com fator APB para o Brasil, conforme trabalho de Hunter et al. (2014).

\subsubsection{Parte I: CAPM, Fama-French e Carhart}

As tabelas apresentadas nessa subseção reportam as regressões dos modelos CAPM, Fama-French e Carhart para todos os fundos da base de dados utilizada e por categoria ANBIMA. Os modelos citados são usados para avaliação do desempenho de ações e fundos de ações, regredindo o retorno em excesso dos ativos em função de fatores de risco sistemáticos. Os parâmetros encontrados mostram a sensibilidade dos fundos à estratégias de investimento na carteira de mercado, tamanho, valor e momento, conforme documentadas por Fama e French (1993) e Carhart (1997). A primeira coluna das tabelas se refere às variáveis das estimações, seguida dos coeficientes calculados com os três modelos propostos. O número de fundos, observações e testes de ajuste estão reportados na parte inferior das tabelas.

Na tabela 3 são apresentados os resultados das estimações para todos os fundos da base de dados. Como mencionado anteriormente, ela é formada pelos fundos de ações que estavam em atividade em dezembro de 2017, com mais de 30 meses de histórico de retorno. Com os 1268 fundos da amostra foram feitas 97.965 observações entre os anos de 2007 a 2019. Para selecionar o mais adequado dentre os modelos propostos, fez-se uma avaliação do $R$ - quadrado - aj, que é uma versão do $R$ - quadrado ${ }^{2}$ que ajusta o

\footnotetext{
${ }^{2} \mathrm{O} R$ - quadrado é chamado de coeficiente de determinação e mostra o quanto os dados utilizados nas estimações estão próximos da linha de regressão ajustada. No entanto, ele não apresenta uma estimativa
} 
valor do coeficiente de determinação com relação à quantidade de variáveis preditivas do modelo. Foi possível observar um aumento dos dois coeficientes nos modelos com mais fatores de risco, mostrando que assim como demonstrado por Carhart (1997), o modelo de quatro fatores capta parte do retorno não explicada pelo fator único do CAPM ou pelos fatores do modelo de Fama-French. Uma vez que Fama e French (1993) mostraram que seu modelo de três fatores explica $90 \%$ das variações nos preços das ações em cross-section (cerca de 20 a $30 \%$ a mais do que o CAPM), acredita-se que o modelo empregado é uma forma consistente para fundamentar as análises sobre o retorno dos fundos.

Tabela 3 - Todos os fundos: resultados das regressões com modelo CAPM, 3 fatores de Fama-French e 4 fatores de Carhart

\begin{tabular}{lccc}
\hline \hline VARIÁVEIS & CAPM & FAMA-FRENCH & CARHART \\
\hline RMRF & $0.8268^{* * *}$ & $0.7979^{* * *}$ & $0.8036^{* * *}$ \\
& $(0.0116)$ & $(0.0112)$ & $(0.0102)$ \\
SMB & & $0.1252^{* * *}$ & $0.1352^{* * *}$ \\
& & $(0.0067)$ & $(0.0084)$ \\
HML & & $-0.0258^{* * *}$ & $-0.0245^{* * *}$ \\
& & $(0.0068)$ & $(0.0067)$ \\
WML & & & $0.0167^{* * *}$ \\
& & & $(0.0058)$ \\
Constante & $0.0002^{* * *}$ & $0.0005^{* * *}$ & $0.0003^{* * *}$ \\
& $(0.0000)$ & $(0.0000)$ & $(0.0001)$ \\
\hline Observações & 97,965 & 97,965 & 97,965 \\
R-quadrado & 0.4192 & 0.4250 & 0.4251 \\
Número de fundos & 1,268 & 1,268 & 1,268 \\
AIC & -307271 & -308238 & -308260 \\
BIC & -307261 & -308210 & -308222 \\
R-quadrado-aj & 0.419 & 0.425 & 0.425 \\
\hline \hline
\end{tabular}

Estimação dos modelos CAPM, 3 Fatores de Fama-French e 4 Fatores de Carhart por MQO com efeito fixo. A variável dependente é o excesso de retorno. Os erros padrão estão entre parênteses abaixo do parâmetro estimado. A significância estatística de 10\%, 5\% e $1 \%$ está indicada por $*, * * \mathrm{e}^{* * *}$, respectivamente.

O teste Critério de Informação de Akaike (AIC) e o Critério Bayesiano de Schwarz (BIC) também contribuem com a escolha do modelo mais apropriado, resultando em valores menores na medida que o ajuste dos modelos melhora. Exibindo valores negativos confiável para comparar modelos com número de fatores diferentes, pois seu valor aumenta com o acréscimo de variáveis explicativas. 
diante dos modelos propostos, os dois critérios também mostram melhora preditiva com a adição de fatores de risco. A significância estatística dos parâmetros mostra que todos eles são significantes a 1\% ou seja, os resultados apresentam $99 \%$ de confiança.

$\mathrm{Na}$ comparação entre o modelo de três e quatro fatores os resultados evidenciam que apesar de semelhantes, o modelo de Carhart descreve melhor o comportamento dos retornos. Por esse motivo, apenas as estimações com o modelo de quatro fatores serão discutidas. Coeficientes positivos associados aos fatores de risco indicam aumento dos retornos com o acréscimo nos valores dessas variáveis. Em uma comparação entre o CAPM e o modelo de três fatores, Fama e French (1993) explicam que se o módulo dos coeficientes convergirem para 1, significa que os fatores de risco adicionados captam a parcela do retorno que não é explicada pelo fator do mercado. No entanto, os resultados apresentados na tabela mostram que os fundos são bastante sensíveis às flutuações do mercado.

O coeficiente do prêmio pelo risco do mercado revela que para cada aumento do Ibovespa sobre a taxa CDI, os fundos alcançaram retorno de $80 \%$ sobre o valor do incremento. Apesar de serem bastante pequenos os coeficientes dos outros fatores de risco, todos são significativos a $1 \%$. Os fundos se mostraram menos sensíveis às variações do fator WML, que apresentou a estratégia de momento como a de maior prêmio pelo risco. Por esse motivo, pode-se inferir que apesar de ser mais rentável investir em ações com bom desempenho passado, essa estratégia foi pouco aproveitada pelos fundos. Vale ressaltar que Carhart (1997) confirma que a maior parte dos ganhos obtidos pelos fundos com a estratégia de momentum acabam consumidos pelas altas taxas e despesas de transação decorrentes da gestão ativa. O coeficiente positivo para SMB (que apresentou prêmio de risco negativo) indica que além de as empresas com alta capitalização de mercado terem alcançado melhores rendimentos, a estratégia de investir nas Big Caps impactou positivamente sobre os ganhos, reforçando o resultado de Jr. e Neves (2000) que também se contrapõe ao encontrado por Fama e French (1993).

A inclinação de HML também exibiu valor negativo, que em conjunto com a média negativa da carteira revela que no Brasil, assim como o padrão verificado por Fama e French (1993) e Carhart (1997), a estratégia de investir em empresas de valor se mostrou mais rentável para os fundos do que as empresas de crescimento. Essa abordagem está alinhada com os resultados de Haugen (1995), indicando que esse comportamento se deve à capacidade das empresas com alto $\mathrm{BE} / \mathrm{ME}$ melhorarem seus rendimentos por meio de 
processos mais complexos de reestruturação. De acordo com Fama e French (1993), ações de crescimento (baixo BE/ME) são mais voláteis e apresentaram coeficiente entre -1 e 0 para o mercado norte americano diante diante do retorno positivo para a carteira do fator HML. Os autores também explicam que os alto retorno alcançados pelas empresas de crescimento se devem à estratégias associadas a maiores riscos.

A diferença entre o retorno observado e o esperado com os modelos de desempenho é dada pelo coeficiente alfa, que de acordo com Gorman e Weigand (2009) representa uma medida da habilidade superior dos gestores. Dessa forma, não se verificou a presença de gestores com desempenho anormal para o mercado brasileiro, corroborando com o resultado de Nerasti e Lucinda (2016) e o de Carhart (1997) para os Estados Unidos. O intercepto próximo de zero também demostra que os fatores de risco do modelo de quatro fatores explicam quase que a totalidade dos retornos médios dos fundos.

A tabela 4 exibe os resultados das estimações do modelo de quatro fatores de Carhart para os fundos de mesma categoria ANBIMA. Apesar de os modelos CAPM e de três fatores de Fama-French também terem sido usados nas estimações dessas carteiras, o modelo de Carhart mostrou maior poder explicativo para quase todas as categorias e por esse motivo, foi o escolhido para a interpretação dos resultados.

O número de observações reflete a quantidade de fundos presente em cada carteira, mostrando que os fundos da categoria Ativos são a maioria, seguidos dos Específicos, Investimento no Exterior e por último, os Indexados. $\mathrm{O}$ valor de $R$-quadrado e $R-$ quadrado-aj indicam que o modelo de Carhart explica a variação transversal nos retornos de todas as categorias, exceto Investimento no exterior, para a qual ele explica apenas $7 \%$ dos rendimentos da carteira. Para esses fundos, o coeficiente de determinação foi baixo com todos os modelos testados no entanto, o modelo de Carhart apresentou o melhor ajuste que os demais (ver tabela 9 do apêndice C). Esse resultado pode ser explicado em razão da exigência regulatória de que os fundos dessa categoria invistam mais de $40 \%$ do seu patrimônio líquido em ativos no exterior. Dessa forma, é de se esperar que carteiras com ativos nacionais não expliquem a maior parte do retorno alcançado. No entanto, como os coeficientes calculados para a categoria Inv. no Exterior foram quase todos significativos a 1\%, mostrando que eles podem explicar a parte dos retornos devida ao investimento em ativos nacionais. 
Tabela 4 - Resultados das regressões com o modelo de quatro fatores de Carhart para os fundos de ações, agrupados por categoria ANBIMA.

\begin{tabular}{lcccc}
\hline \hline VARIÁVEIS & ATIVOS & ESPECÍFICOS & INDEXADOS & INV. EXTERIOR \\
\hline RMRF & $0.7837^{* * *}$ & $1.1676^{* * *}$ & $1.0225^{* * *}$ & $0.4336^{* * *}$ \\
& $(0.0082)$ & $(0.0480)$ & $(0.0185)$ & $(0.0523)$ \\
SMB & $0.1873^{* * *}$ & $-0.2628^{* * *}$ & 0.0014 & $0.1649^{* * *}$ \\
& $(0.0077)$ & $(0.0335)$ & $(0.0115)$ & $(0.0300)$ \\
HML & $-0.0554^{* * *}$ & $0.3324^{* * *}$ & $0.0226^{* *}$ & -0.0224 \\
& $(0.0064)$ & $(0.0344)$ & $(0.0090)$ & $(0.0218)$ \\
WML & $0.0638^{* * *}$ & $-0.3850^{* * *}$ & $-0.0392^{* * *}$ & $0.0513^{* * *}$ \\
& $(0.0042)$ & $(0.0204)$ & $(0.0061)$ & $(0.0168)$ \\
Constante & $0.0001^{* * *}$ & $0.0008^{* * *}$ & $-0.0021^{* * *}$ & $0.0029^{* * *}$ \\
& $(0.0001)$ & $(0.0003)$ & $(0.0001)$ & $(0.0002)$ \\
\hline Observações & 76,258 & 9,335 & 4,298 & 8,074 \\
R-quadrado & 0.5493 & 0.4774 & 0.8801 & 0.0750 \\
Número de fundos & 995 & 98 & 49 & 126 \\
AIC & -285885 & -20388 & -21399 & -16812 \\
BIC & -285848 & -20359 & -21374 & -16784 \\
R-quadrado-aj & 0.549 & 0.477 & 0.880 & 0.0745 \\
\hline \hline
\end{tabular}

Estimação do modelo de 4 Fatores de Carhart por MQO com efeito fixo. A variável dependente é o excesso de retorno. Os erros padrão estão entre parênteses abaixo do parâmetro estimado. A significância estatística de $10 \%, 5 \%$ e $1 \%$ está indicada por *, ** e ***, respectivamente.

O coeficiente do prêmio pelo risco de investimento no mercado de ações (RMRF) foi significativo a $1 \%$ para todas as categorias. Os valores próximos de 1 exibidos para Ativos, Específicos e Indexados revelam que a parte do retorno desses fundos relacionada com o risco do mercado brasileiro sofre variação nas mesmas proporções que ele. Fazendo uma média entre os coeficientes dessas três categorias, é possível observar que os fundos de Investimento no Exterior são menos sensíveis aos riscos do mercado brasileiro (com $\beta_{1}$ médio igual a 0,4336$)$. Esse resultado já era esperado pela maior concentração dos investimentos desses fundos em mercados de outros países. Apesar de os dados apresentados não serem suficientes para encontrar a causa, o coeficiente de 0,7827 observado nos fundos Ativos pode ser decorrente da heterogeneidade dessa categoria, uma vez que ela é dividida em 7 subcategorias com diferentes estratégias de investimento. Por poderem operar mais livremente, existe a possibilidade de que os fundos de ações Ativos da subcategoria livre tenham buscado mais oportunidades nos mercados internacionais, causando uma diminuição no impacto observado do prêmio de risco associado ao mercado brasileiro. 
Diante desse argumento, os parâmetros estimados para os outros fatores também seriam influenciados.

Fundos Indexados buscam carregar na carteira as mesmas posições do índice de referência que ele pretende replicar, o que pode explicar seu comportamento muito próximo da carteira de mercado, calculada com o índice Bovespa. No entanto, apesar de o prêmio de mercado também ser positivo para esses fundos, eles apresentaram retorno ${ }^{3}$ negativo no período, mostrando que apesar do bom resultado com relação ao risco de mercado, outra variável destruiu valor para a categoria. O fator SMB não apresentou coeficiente estatisticamente significante para os fundos Indexados. Já os Ativos e Inv. no Exterior apresentaram coeficientes positivos para a carteira de tamanho, que apresentou retorno negativo nas duas categorias (tabela 1), mostrando que esses fundos ganharam valor com o desempenho das empresas Big. Para os fundos Específicos SMB apresentou valor positivo de $0,06 \%$ que associado com o beta negativo estimado, reflete a mesma tendência encontrada nas outras categorias. A magnitude dos coeficientes revela que os fundos Específicos, são os mais afetados pelas variações nos retornos das grandes empresas, seguidos pelos fundos Ativos e por último os Inv. no Exterior. A convergência entre os resultados para o prêmio de risco do fator SMB reforça a análise inicial feita para toda a amostra (representando uma generalização do comportamento das quatro categorias), de que os fundos brasileiros alcançam maiores retornos investindo nas grandes companhias, com ativos conhecidos como Blue Chips. A tendência verificada corrobora com os resultados de Jr. e Neves (2000).

Como mencionado anteriormente, o retorno de HML calculado é negativo para toda a amostra. As estimações para esse fator não apresentaram coeficiente significativo apenas para a categoria Inv. no Exterior. Os fundos mais sensíveis à estratégia de valor em ordem decrescente são os Específicos, Ativos e Indexados. A tabela 4 revela comportamento contrário dos fundos Ativos com relação aos demais. A categoria foi a única a apresentar prêmio de risco positivo para o fator HML, ocasionado pelo valor negativo do coeficiente estimado. Fundos Específicos e Indexados no entanto, performaram mal no período diante da carteira de valor, que exibiu prêmio negativo. Fama e French (1993) verificaram a mesma tendência em HML reduzir a média dos retornos de algumas das carteiras estudadas,

\footnotetext{
${ }^{3} \mathrm{O}$ excesso de retorno dado por Ret é o retorno líquido da carteira estudada que está acima da taxa CDI, usada como proxi para o ativo livre de risco.
} 
pois apesar de o fator de risco apresentar sinal positivo na amostra dos autores, o beta associado a ele apresentou-se em média negativo.

Apesar de os coeficientes de WML revelarem pouco impacto da estratégia de momento sobre os fundos (exceto para a categoria Específicos, que demonstrou alta sensibilidade ao fator), todos eles foram significativos a 1\%. Quando associados ao retorno médio positivo da carteira, o sinal dos coeficientes revela que fundos Específicos e Indexados perderam valor associado ao momentum. Aparentemente, esses fundos mantiveram suas "apostas"em empresas que vinham performando mal. A perda para de $43 \%$ para os Específicos, ocasionada pelo fator, foi consideravelmente alta. Vale ressaltar que o excesso de retorno é uma soma de fatores, então esse resultado não significa diminuição nessa mesma taxa sobre o desempenho desses fundos. Os Indexados sofreram perda associada bem menor, de 4,8\%, enquanto os Ativos e Indexados alcançaram prêmio positivo de 8,4\% e 7\%, respectivamente. Significa dizer que a diferença entre o desempenho superior dos ativos Winners sobre os Losers impactou de forma positiva para as categorias Ativos e Inv. no Exterior e negativa para Específicos e Indexados. Pode-se inferir portanto, que o excesso de retorno negativo encontrado para os fundos Específicos e Indexados também pode ser resultado de uma deficiência dessas categorias em seguir a estratégia de comprar ativos com bom histórico de rendimentos.

A gestão passiva pode explicar esse resultado, uma vez que a categoria Indexados não altera constantemente a composição da sua carteira (como no gerenciamento ativo) para aproveitar novas oportunidades, buscando carregar nela os mesmos ativos que o índice de referência que pretendem replicar. No entanto, essa exposição é mais baixa em razão de esses fundos também serem obrigados a aplicar os recursos remanescentes em caixa em cotas de fundos de renda fixa de baixa duração. O mesmo argumento pode ser aplicado aos fundos Específicos, formados pelas subcategorias FMP-FGTS ${ }^{4}$, Fechados de Ações e Monoação (que por apresentarem estratégias de investimento bastante distinta dos demais, uma vez que concentram seu PL em ações de apenas uma empresa, são entendidos como um caso particular e foram omitidos da base de dados). Por serem impossibilitados de operar sua carteira escolhendo livremente entre os papéis Winners, os fundos FMP-FGTS também sofrem perdas com a estratégia de momento.

\footnotetext{
${ }^{4}$ Fundos Específicos FMP-FGTS são Fundos Mútuos de Privatização (FMP) de condomínio aberto, que permitem investir os recursos do FGTS em ações de empresas estatais que foram privatizadas.
} 
Os resultados mostram que o RMRF foi o único fator que impactou positivamente sobre os retornos de todas as categorias analisadas, explicando parte significativa dos rendimentos dos fundos Específicos, apresentou a menor contribuição nos lucros dos fundos Inv. no Exterior. Diferentemente do padrão esperado em que os ativos norte americanos de empresas com baixa capitalização de mercado (Small) geram valor, o desempenho médio desses papéis destruiu valor para os fundos brasileiros, mostrando que as grandes companhias (com ativos popularmente conhecidos como Blue Chips) se apresentaram mais rentáveis no Brasil, independente da categoria.

Ativos das empresas com alto índice BE/ME, adicionaram valor apenas para a categoria Ativos (nos fundos Investimento no exterior o parâmetro calculado não foi significativo), mesmo que a uma taxa pequena (0,05\%), mostrando que empresas com baixa capitalização de mercado apresentam melhores rendimentos. Ações com baixo $\mathrm{BE} / \mathrm{ME}$ estão associadas a maiores riscos e consequentemente maiores oportunidades de retorno. Por último, o fator WML explica boa parte do rendimento oferecido pelos fundos Específicos, impactando de forma negativa sobre eles. Esse impacto também pode ser observado na categoria Indexados, na qual o fator de momento revelou ser a explicação para o retorno negativo apresentado. Em suma, os fundos que tiveram maiores retornos (em ordem decrescente) associados ao fator de mercado foram respectivamente Específicos, Indexados, Ativos e Inv. no Exterior, ao fator tamanho foram Inv. no Exterior, Ativos e Específicos, ao fator de valor foram Específicos, Ativos e Indexados e ao fator de momento foram Específicos, Ativos, Inv. no Exterior e Indexados.

A constante nos modelos de avaliação de ativos representa uma especificidade de cada fundo, entendida como a habilidade dos gestores em gerar valor sobre os retornos por meio do gerenciamento ativo da carteira de investimento. Ela foi bastante próxima de zero para os fundos Ativos, o que significa dizer que os fatores de risco explicam quase a totalidade dos retornos dessa categoria, não apresentando evidência de performance superior dos gestores. Para os fundos Específicos e Inv. no Exterior, apesar de pequena, a constante calculada mostra que existem gestores qualificados para gerar retornos anormais positivos. Por serem considerados fundos de gestão passiva (uma vez que apenas buscam alinhar suas carteiras com os ativos que compõe as carteiras de índices de referência), a média dos alfas encontrada na categoria Indexados foi negativa (além de apresentar maior 
em magnitude) para os fundos Indexados, mostrando a inabilidade dos gestores em de gerar valores positivos sobre os retornos.

\subsubsection{Parte II: Modelo com fator APB}

Como o fator APB é formado pelo termo de erro da regressão estimada por MQO, ele constitui uma variável aleatória com média zero. Dessa forma, ele não altera o valor dos parâmetros calculados. Fundos que não fazem uso de ferramentas comuns e seu rendimento vem exclusivamente da habilidade dos gestores, exibirão coeficientes para o fator APB e APB-ajustado iguais a zero $\left(\lambda_{i}=\gamma_{i}=0\right)$. De maneira contrária, se os resultados dos fundos forem provenientes apenas das estratégias seguidas pelas categorias ou mais ainda, estratégias de subgrupos dessas categorias, então os interceptos $a_{i}$ e $a_{i}^{a j}$ estimados respectivamente com o modelo das equações (14) e (15) serão iguais a zero. Vale ressaltar que assim como no trabalho de Hunter et al. (2014), as análises serão feitas sobre a porcentagem de aumento ou diminuição na quantidade de contantes significativas e não sobre a magnitude dos alfas encontrados para os fundos. O aumento da significância contribui com a escolha dos investidores por fundos com gestores mais qualificados dentro de um grupo com estratégias de investimento semelhantes, representado pelas categorias ANBIMA.

A tabela (5) apresenta o percentual de fundos com parâmetros significativos e não significativos. A estimação dos interceptos $\alpha_{i}, a_{i}$ e $a_{i}^{a j}$ (colunas 1, 2 e 3) foi feita respectivamente com o modelo de quatro fatores de Carhart (equação 6), o modelo com fator APB (equação 14) e o modelo com fator APB-ajustado (equação 15), além dos coeficientes $\lambda_{i}$ e $\gamma_{i}$ (colunas 4 e 5) dos dois últimos modelos. A variável dependente é o Ret - bruto ou seja, o retorno alcançado pelos fundos antes de serem descontadas as taxas e despesas cobradas por eles. Essa abordagem tem o objetivo de concentrar as análises no desempenho total alcançado, não apenas na parcela do desempenho entregue aos investidores, uma vez que essas tarifas acabam por consumir boa parte do retorno, como explica Carhart (1997). Os resultados são exibidos por categoria ANBIMA, que agrupa os fundos de acordo com suas estratégias de investimento.

A coluna (1) mostra que por meio do modelo de quatro fatores de Carhart, 16,82\% dos fundos Ativos apresentaram alfas positivos e 4,92\% apresentaram alfas negativos, 
Tabela 5 - Percentual de fundos com coeficientes alfa estimados significativos e não significativos

Os parâmetros apresentados em porcentagem se referem às estimações com os modelos: (1) quatro fatores de Carhart (equação 6: $R_{i t}-R_{f t}=\alpha_{i t}+\beta_{1 i t} R M R F_{t}+\beta_{2 i t} S M B_{t}+$ $\beta_{3 i t} H M L_{t}+\beta_{4 i t} W M L_{t}+\epsilon_{i t}$ ); (2) e (4) quatro fatores de Carhart com fator APB (equação 14): $r_{i, t}=a_{i}+\beta_{1, i}\left(R M R F_{t}\right)+\beta_{2, i} S M B_{t}+\beta_{3, i} H M L_{t}+\beta_{4, i} W M L_{t}+\lambda_{i} A P B_{j, t}+\varepsilon_{i, t}$; (3) e (5) o modelo de quatro fatores de Carhart com fator APB-ajustado (equação 15: $\left.r_{i, t}=a_{i}^{a j}+\beta_{1, i}\left(R M R F_{t}\right)+\beta_{2, i} S M B_{t}+\beta_{3, i} H M L_{t}+\beta_{4, i} W M L_{t}+\gamma_{i} A P B_{j, t}^{a j}+\varepsilon_{i, t}\right)$. Considerou-se os fundos com mais de 30 meses de negociação consecutiva no período de 2009 a 2017. A variável dependente é o Ret-bruto, calculado com a soma entre o excesso de retorno e as taxas cobradas pelos fundos. $N$ representa o número de observações em cada grupo. Os dados sobre os fundos foram extraídos da base de dados da Economática, e os valores referentes aos fatores de risco disponibilizados pelo NEFIN.

\begin{tabular}{|c|c|c|c|c|c|}
\hline & $\begin{array}{l}\text { (1) } \\
\alpha_{i}\end{array}$ & $\begin{array}{l}(2) \\
a_{i}\end{array}$ & $\begin{array}{l}(3) \\
a_{i}^{a j}\end{array}$ & $\begin{array}{c}\text { (4) } \\
\lambda_{i}\end{array}$ & $\begin{array}{l}(5) \\
\gamma_{i}\end{array}$ \\
\hline \multicolumn{6}{|l|}{ Ativos (\%) } \\
\hline Positivo e significativo & 16.82 & 23.30 & 0.66 & 74.02 & 74.02 \\
\hline Positivo e não-significativo & 45.24 & 39.52 & 42.54 & 19.90 & 19.90 \\
\hline Negativo e significativo & 4.92 & 6.91 & 2.82 & 0.74 & 0.74 \\
\hline Negativo e não significativo & 33.01 & 30.26 & 53.98 & 5.34 & 5.34 \\
\hline$N$ & 75641 & 75641 & 75641 & 75641 & 75641 \\
\hline \multicolumn{6}{|l|}{ Específicos (\%) } \\
\hline Positivo e significativo & 0.00 & 0.00 & 0.00 & 86.33 & 86.33 \\
\hline Positivo e não-significativo & 42.59 & 42.59 & 49.43 & 6.51 & 6.51 \\
\hline Negativo e significativo & 4.37 & 4.70 & 4.37 & 1.16 & 1.16 \\
\hline Negativo e não-significativo & 53.04 & 52.71 & 46.20 & 6.00 & 6.00 \\
\hline$N$ & 9284 & 9284 & 9284 & 9284 & 9284 \\
\hline \multicolumn{6}{|l|}{ Indexados (\%) } \\
\hline Positivo e significativo & 1.40 & 1.40 & 0.00 & 92.42 & 92.42 \\
\hline Positivo e não-significativo & 9.96 & 8.75 & 61.35 & 7.58 & 7.58 \\
\hline Negativo e significativo & 5.03 & 35.95 & 0.00 & 0.00 & 0.00 \\
\hline Negativo e não-significativo & 83.62 & 53.91 & 38.65 & 0.00 & 0.00 \\
\hline$N$ & 4298 & 4298 & 4298 & 4298 & 4298 \\
\hline \multicolumn{6}{|l|}{ Inv. Exterior (\%) } \\
\hline Positivo e significativo & 11.46 & 14.54 & 1.06 & 64.80 & 64.80 \\
\hline Positivo e não-significativo & 61.35 & 57.28 & 49.31 & 24.15 & 24.15 \\
\hline Negativo e significativo & 3.75 & 3.75 & 1.86 & 0.00 & 0.00 \\
\hline Negativo e não-significativo & 23.44 & 24.43 & 47.76 & 11.05 & 11.05 \\
\hline$N$ & 7889 & 7889 & 7889 & 7889 & 7889 \\
\hline
\end{tabular}


ambos significativos. Isso quer dizer que no período analisado, a quantidade de gestores com desempenho satisfatório na categoria foi três vezes maior do que com desempenho insatisfatório. No entanto, a maior parte da amostra não apresentou resultado estatisticamente significativo. O modelo com fator APB propõe melhorar a significância das estimações, o que pode ser observado pela diminuição de alfas não significativos da coluna (2) com relação à coluna (1).

Os $\alpha_{i}$ da primeira coluna também mostraram que interessantemente, para todas as categorias, em torno de $4 \%$ dos alfas foram negativos e significativos (com p-valor menor do que 2,5\%), evidenciando baixa performance dos gestores. Apesar disso, somente os fundos Específicos não apresentaram alfas positivos e significativos (com Ret - bruto como variável dependente) evidenciando que na média, os gestores dessa categoria não apresentaram resultados satisfatórios. Esse resultado difere do apresentado na tabela $4 \mathrm{em}$ que a variável dependente é o excesso de retorno (Ret), que é líquido das taxas e despesas cobradas pelos fundos. Nas estimações da parte I, os fundos Específicos apresentaram alfa médio positivo $(0,08 \%)$, o que mostra a importância de incluir as taxas para a correta avaliação da habilidade dos gestores. Outra diferença significativa com a mudança da variável dependente foi observada nos fundos Indexados, que inicialmente apresentaram alfas médios negativos (-0,21\%), e com o Ret - bruto mostrou que 1,4\% dos gestores alcançaram desempenho positivo. Essas diferenças podem ser explicadas devido ao alto número de alfas não significativos encontrados nas duas categorias citadas (em torno de $95 \%$ ). Mais de $11 \%$ dos fundos Ativos e Inv. no Exterior apresentaram resultados consistentes com uma boa gestão. No entanto, enquanto os Específicos exibiram a maior quantidade de fundos com gestores qualificados (capazes de gerar alfa positivo) calculados com o Ret, com o Ret - bruto esse desempenho ficou para a categoria Ativos.

Os resíduos mensais da regressão da coluna 1 foram usados para formar o fator APB, que representa a parcela dos retornos inerente ao risco idiossincrático assumido pelos fundos. A coluna 2 exibe os alfas, chamados de $a_{i}$, calculados com a adição do fator APB ao modelo de Carhart (1997). Se o fator APB captura esse co-movimento, a estatística $t$ dos coeficientes calculados com ele aumenta. Então, a média de fundos com p-valor significante (abaixo de 2,5\%, que corresponde a região de confiança de duas caldas de 95\%) aumenta, assim como verificado pela maioria das categorias na tabela. A diferença entre a quantidade de valores significativos das colunas 1 e 2 evidencia a existência de ferramentas 
comuns entre as estratégias de investimento da mesma categoria para gerar retorno. No entanto, essas estratégias destruíram valor para os fundos Específicos e Indexados, aumentando somente a quantidade de alfas negativos nessas categorias (enquanto os alfas positivos permaneceram os mesmos) e agregaram valor para os Ativos e Inv. no Exterior, observado com o aumento no número de alfas positivos.

O alfa ajustado da coluna 3 foi empregado conforme a equação 15, para identificar se dentre os fundos com estratégias semelhantes existem gestores com ferramentas únicas para gerar retornos, ou seja, não encontrados entre subgrupos nas categorias. Se a quantidade de $a_{i}^{a j}$ significativos diminui, significa dizer que essas ferramentas comuns de subgrupos não foram encontradas. Essa característica foi claramente observada na categoria Indexados, que apesar de apresentarem alfas gerados comumente pela categoria (observado por $a_{i}$ ), não apresentaram fluxos relacionados a subgrupos. Usando o modelo com alfa ajustado, os fundos Específicos mostraram quase a mesma quantidade de fluxos decorrentes de estratégias comuns em grupos e subgrupos no entanto, novamente elas foram negativas, reduzindo o retorno alcançado.

Os fundos Ativos exibiram pouco co-movimento para subgrupos, diferentemente do esperado para a categoria, uma vez que ela apresenta sete subcategorias com diferenças relevantes nas estratégias. No entanto, esse resultado pode ser explicado pelo aumento dos coeficientes não significativos. Uma diminuição na quantidade de fundos com alfas significativos do modelo ajustado com relação ao alfa do $\operatorname{APB}\left(a_{i}^{a j}<a_{i}\right)$, como a observada em todas as categorias, revela que apesar de existirem poucos subgrupos, suas estratégias reduziram o retorno dos fundos, demonstrando mais alfas ajustados negativos do que positivos. O trabalho de Hunter et al. (2014) encontrou uma diminuição na quantidade de fundos com alfas significativos positivos e um aumento nos negativos, indicando que as estratégias comuns dos grupos estudados por ele são geralmente positivas.

Nos modelos com APB e APB-ajustado, se os coeficientes $\lambda_{i}$ e $\gamma_{i}$ (colunas 5 e 6) forem negativos, significa dizer que os gestores seguiram estratégias contrárias às verificadas em cada grupo e subgrupo (respectivamente). Não foram encontrados fundos com esse comportamento entre os fundos Indexados e Inv. no Exterior. A consistência desse resultado pode ser verificada pelas estratégias dessas categorias, uma vez que na primeira os fundos buscam replicar as carteiras dos Índices de referência e portanto, geralmente apresentarão os mesmos carregamentos que elas. Na segunda categoria, grande parte dos 
investimentos devem necessariamente ser aplicados em mercados de outros países. Já nos fundos Ativos e Indexados, apesar de verificada a existência de algum movimento idiossincrático negativo, a extensa maioria dos fundos acompanha o co-movimento dessas estratégias.

Os resultados com adição do fator APB ao modelo de quatro fatores de Carhart mostram que na categoria Ativos é verificada a maior existência de habilidade dos gestores entre as categorias, sendo que a maior parte deles acompanha estratégias positivas comuns na categoria e em alguns subgrupos existentes nela. Embora a taxa de coeficientes não significativos encontrados entre os fundos Específicos tenha sido bastante elevada, em alguns fundos dessa categoria, os métodos comuns utilizados pelos gestores destruíram valor sobre o retorno. Na categoria Indexados, poucos gestores mostraram habilidade em gerar ou destruir valor, sendo que a maioria dos fundos que seguiram as estratégias de seus pares perderam parte do lucro da categoria. Por último, os fundos Inv. no Exterior também apresentaram alta taxa de coeficientes não significativos no entanto, todos os fundos acompanharam o retorno das estratégias de seus pares que foi positiva para a maioria deles.

Os resultados dessa tabela estão de acordo com os apresentados por Hunter et al. (2014), em que o aumento na quantidade de coeficientes alfas significativos comprova a melhora na estimação dos parâmetros alfa do modelo com fator APB em relação ao modelo proposto por Carhart (1997) aumentando a estatística $t$ sem no entanto, alterar o valor dos parâmetros estimados (uma vez que o APB é construído com os termos de erro que possuem média zero). Além disso, a alta taxa de fundos com coeficientes $\lambda_{i}$ e $\gamma_{i}$ positivos e significativos mostraram que quando existentes, as estratégias do grupo são acompanhadas pela maioria deles. 


\section{Conclusão}

Tendo se tornado o oitavo maior do mundo em 2017, o mercado brasileiro de fundos de investimento constitui um importante tema de pesquisa. De acordo com a International Investment Funds Association (IIFA, 2018), o patrimônio líquido da indústria brasileira contabilizou 3,4 trilhões de reais no período. No entanto, o Brasil costuma oferecer altas taxas de juros para o mercado de renda fixa, diminuindo o interesse dos investidores por ativos de renda variável e fazendo com que os fundos de ações correspondam a apenas $5 \%$ da indústria. Os fundos brasileiros são constituídos como uma espécie de condomínio, em que os investidores compram cotas que são parcelas ideais do patrimônio líquido. Eles oferecem o benefício de uma gestão profissional dos recursos, que são investidos coletivamente, diluindo as despesas diante do aumento na capacidade de diversificação das carteiras de investimento. Outra vantagem é a facilidade de acompanhamento, oferecida por meio do envio periódico de relatórios, além da praticidade no pagamento de impostos. A CVM e a ANBIMA são as entidades encarregadas de aumentar a transparência do mercado fiscalizando, regulando, informando e normatizando. Em 2015 a ANBIMA apresentou uma nova classificação para os fundos, dividindo-os de acordo com o tipo (classes) e estratégias de investimento (categorias). O propósito da nova regulamentação foi a busca pela internacionalização dessa indústria diante de grandes mercados, além de melhorar o processo de investimento.

Diante do volume e crescimento do setor, este trabalho buscou analisar o desempenho de fundos de ações brasileiros, observando a influência de fatores de risco comuns sobre o retorno alcançado por eles. O objetivo é contribuir com o processo de investimento, identificando características que agregam ou destroem valor, considerando as especificidades de cada categoria. O período analisado foi de janeiro de 2009 a dezembro de 2017. Foram utilizados dados de 1268 fundos brasileiros que estavam em atividade no final desse período. Para evitar o viés de incubação documentado por Carhart (1995), foram retirados da amostra os fundos com menos de 30 meses consecutivos de histórico de retorno. A base de dados da Economática forneceu todas as informações relativas aos fundos de investimento como classificação, retorno, taxas e regulamento (usados apenas para consulta). Valores relativos aos fatores de risco são disponibilizados pelo NEFIN, onde são calculados diariamente desde 2001. 
A vasta literatura sobre o tema apresenta diversos modelos, presentes no ambiente estabelecido desde a Teoria de Carteiras formulada por Markowitz (1952) até os modelos que buscam explicar o retorno com diferentes (e algumas vezes numerosos) fatores de risco exógenos, criando um fenômeno apelidado por Cochrane (2011) de Factor-zoo. Talvez por sua conhecida simplicidade e praticidade, o modelo tradicional mais utilizado pelo mercado é o CAPM, que estabelece uma relação linear entre o retorno alcançado e o prêmio inerente ao risco de mercado. No entanto, muito se discute na literatura sobre a eficiência deste modelo, que acaba omitindo outras variáveis que também podem impactar nos resultados, como demonstrado por Fama e French (1993) e Carhart (1997), por exemplo. Por esse motivo, o modelo econométrico escolhido para este trabalho foi o de quatro fatores de Carhart, que além de indicar a parcela dos retornos devida ao risco de mercado, tamanho e valor, também inclui o risco devido ao momentun, de Jegadeesh e Titman (1993).

No entanto, se esses fatores não explicarem totalmente o retorno sistemático de um ativo a parcela de alguma possível variável omitida do modelo é capturada pelo termo de erro. Em análises ao longo do tempo essa ocorrência acaba por produzir resíduos correlacionados que podem enviesar os resultados. Por esse motivo, na segunda parte desse trabalho considerou-se a existência de estratégias de investimento comuns entre grupos de mesma categoria. Assim, adicionou-se ao modelo de quatro fatores de Carhart um novo fator chamado de Active Peer Benchmarck (APB), conforme documentado por Hunter et al. (2014). Por capturar o movimento idiossincrático comum dos fundos de investimento, o fator diminui os erros estimados do modelo, melhorando a significância estatística dos coeficientes (verificadas com p-valor menor do que 2,5\%) sem alterar o valor deles. Dessa forma, o fator também contribui com uma análise mais precisa da constante alfa do modelo, que indica o desempenho dos gestores em gerar valor. A adição do fator APB ao modelo de Carhart procura corrigir esse problema. Além disso, ela constitui uma contribuição original deste trabalho às pesquisas sobre a avaliação de fundos no Brasil.

A análise do painel não balanceado foi feita em cross-section pelo método dos Mínimos Quadrados Ordinários com efeito fixo. A variável dependente comumente usada na avaliação do retorno gerado pelos fundos é o excesso de retorno, calculado como a parcela líquida dos rendimentos acima da taxa livre de risco (CDI). Na segunda parte foram acrescentados dados sobre as taxas cobradas pelos fundos, para calcular o excesso de retorno bruto gerado por eles. Essa mudança direciona as análises para os resultados alcançados 
pelos fundos ao invés do entregue para os investidores, como explicam Carhart (1997) e Castro e Minardi (2009). Uma comparação feita com os resultados dos modelos CAPM, três fatores de Fama-French e quatro fatores de Carhart evidenciou uma melhora na capacidade explicativa do último modelo em relação aos primeiros, assim como documentado por Carhart (1997) e Nerasti e Lucinda (2016).

A maior volatilidade nos rendimentos foi encontrada para os fundos Específicos, com desvio padrão médio de 11,25\%, a categoria também apresentou o menor retorno líquido, ficando 0,2\% abaixo do CDI no período. Os fundos Ativos correspondem a 78\% das observações. Apesar do excesso de retorno positivo, esta categoria apresentou as maiores taxas (como esperado para estratégias ativas de formação das carteiras), com uma diferença de 0,32\% entre o retorno bruto e líquido. Esse resultado reforça a afirmação de Castro e Minardi (2009) e Carhart (1997), de que as taxas destroem a maior parte do valor alcançados pelos gestores.

Os retornos apresentados para os fatores do modelo mostram que assim como encontrado por Nerasti e Lucinda (2016), o fator WML foi o que ofereceu maior prêmio de risco. No entanto, a análise dos coeficientes de cada categoria revelou que os fundos são mais sensíveis às flutuações do fator de mercado, o RMRF. O fator SMB calculado foi negativo, revelando que a estratégia de investir nas Big Caps aumentou os rendimentos no período, reforçando o resultado de Jr. e Neves (2000). Para a estratégia de valor, os resultados evidenciaram que no mercado brasileiro foi mais rentável os papéis de empresas com alto índice book-to-market, assim como encontrado por Fama e French (1993) para o mercado norte americano.

A segunda parte deste trabalho incluiu o fator APB para capturar estratégias comuns presentes entre as categorias, melhorando a significância dos parâmetros usados para selecionar gestores habilidosos. Assim, de acordo com o resultado documentado por Borges e Martelanc (2015), foi evidenciada a presença de gestores com habilidade superior em gerar retornos principalmente na categoria Ativos (observada pela quantidade de alfas positivos e significativos). No entanto, para os fundos específicos essas estratégias de grupos acabaram por reduzir os retornos.

Apesar dos resultados consistentes apresentados, existem algumas limitações à essa pesquisa. Erros de medida de variáveis como Ibovespa e a idealização do mercado de investimentos (para inferir a existência de uma carteira de mercado totalmente eficiente) 
por exemplo, acabam interferindo nos resultados. Dessa forma, o ambiente de pesquisa dos tradicionais modelos de fatores ignora a cobrança de impostos e outros custos de transação, além de assumir que a expectativa e informação dos investidores é homogênea. No entanto, a maior parte dos trabalhos apenas busca sanar as deficiências para explicar o retorno por meio da busca de outros fatores exógenos, o que Hsu e Kalesnik (2014) consideram ser apenas para fins de publicação, uma vez que acabam não contribuindo com os investidores de forma prática. Para análises mais precisas, seria interessante examinar as carteiras dos fundos, mas como afirmam Kacperczyk, Sialm e Zheng (2008), existe uma lacuna entre o retorno obtido pelos fundos e o retorno das carteiras divulgadas periodicamente por eles, o que dificulta o uso dessas carteiras como uma ferramenta de estudo. Mesmo diante das dificuldades citadas, espera-se que os resultados deste trabalho possam ajudar os investidores na escolha do fundo de investimento, além de contribuir com o processo de investimento dos gestores, evidenciando as estratégias que foram mais rentáveis no período analisado. 


\section{Referências $^{1}$}

AGNESENS, J. A statistically robust decomposition of mutual fund performance. Journal of Banking Finance, v. 37, n. 10, p. 3867-3877, 2013.

AHARONI, G.; GRUNDY, B.; ZENG, Q. Stock returns and the miller modigliani valuation formula: Revisiting the fama french analysis. Unpublished working paper. University of Melbourne, 2013.

ALVES, A. J. Fundos mútuos de investimento no brasil: A expansão da indústria nos anos 1990 e perspectivas para o futuro. Comissão Econômica para América Latina e o Caribe, 2003. Disponível em: 〈https://repositorio.cepal.org/bitstream/handle/11362/ $28379 /$ LCbrsR143_pt.pdf?sequence=1\&isAllowed $=y\rangle$.

ANBIMA. Classificação de Fundos. 2015. Disponível em: 〈http://www.anbima.com.br/ data/files/E3/62/8C/0B/242085106351AF7569A80AC2/NovaClassificacaodeFundos_ PaperTecnico_1_.pdf $\rangle$.

ANDREZO, A. F.; LIMA, I. S. Mercado financeiro: aspectos históricos e conceituais. 3. ed. [S.1.]: Atlas, 2007.

ARAÚJO, E. A. T.; OliveirA, V. do C.; SILVA, W. A. C. Capm em estudos brasileiros: Uma anÁlise da pesquisa. Revista de Contabilidade e Organizações, v. 6, n. 15, p. 95-122, 2012.

ASNESS, C. S.; MOSKOWITZ, T. J.; PEDERSEN, L. H. Value and momentum everywhere. The Journal of Finance, v. 68, n. 3, p. 929-985, 2013.

B3. História da Bolsa. Disponível em: 〈http://acervob3.com.br/History〉. Acesso em: 29 de ago. de 2020 .

BAKS, K. P.; METRICK, A.; WACHTER, J. Should investors avoid all actively managed mutual funds? a study in bayesian performance evaluation. The Journal of Finance, v. 56, n. 1, p. 45-86, 2001.

BLANCO, B. The use of capm and fama and french three factor model: portfolios selection. Public and Municipal Finance (hybrid), v. 1, n. 2, p. 61-70, 2012.

BORGES, E. C.; MARTELANC, R. Sorte ou habilidade: uma avaliação dos fundos de investimento no brasil. Revista de Administração (São Paulo), v. 50, n. 2, p. 196-207, 2015.

BRAGA, C. A. B. M.; LEAL, R. P. C. Ações de valor e crescimento nos anos 90. Relatório Coppead, Universidade Federal do Rio de Janeiro, v. 330, 2000.

BRITO, N. R. O. Avaliação de desempenho e market timing: O índice de habilidade. Revista Brasileira de Finanças, v. 1, n. 1, p. 1-17, 2003.

BROWN, S. J. et al. Survivorship bias in performance studies. The Review of Financial Studies, v. 5, n. 4, p. 553-580, 1992.

\footnotetext{
${ }^{1}$ De acordo com a Associação Brasileira de Normas Técnicas. NBR 6023.
} 
BROWN, S. J.; GOETZMAnN, W. N. Performance persistence. The Jounal of Finance, n. 50, 1995.

BURMEISTER, E.; ROLL, R.; ROSS, S. A practitioner's guide to arbitrage pricing theory. in a practitioner's guide to factor models. The Research Foundation of the Institute of Chartered Financial Analysts, n. 1-30, 1994.

CARHART, M. M. Survivor bias and persistence in mutual fund performance. Tese (Doutorado) - Graduate School of Business, University of Chicago, 1995.

CARHART, M. M. On persistence in mutual fund performance. The Journal of Finance, v. 52, n. 1, p. 57-82, 1997.

CARHART, M. M. Mutual fund survivorship. USC working paper, v. 97, n. 1, 1997b.

CASTRO, B. R.; MinARDI, A. M. A. F. Comparação do desempenho dos fundos de ações ativos e passivos. Revista Brasileira de Finanças, v. 7, n. 2, p. 143-161, 2009.

CHAN, L. K. C.; HAMAO, Y.; LAKONISHOK, J. Fundamentals and stock returns in Japan. The Journal of Finance, v. 46, n. 5, p. 1739-1764, 1991.

CHAN, L. K. C.; JEGADEESH, N.; LAKONISHOK, J. Momentum strategies. The Journal of Finance, v. 51, n. 5, p. 1681-1713, 1996.

CHEN, H.-L.; JEGADEESH, N.; WERMERS, R. The value of active mutual fund management: An examination of the stockholdings and trades of fund managers. The Journal of Financial and Quantitative Analysis, v. 35, n. 3, p. 343-368, 2000.

CHEN, N.-F.; ROLL, R.; ROSS, S. A. Economic forces and the stock market. The Journal of Business, v. 59, n. 3, p. 383-403, 1986.

COCHRANE, J. H. Presidential address: Discount rates. The Journal of Finance, v. 66, n. 4, p. 1047-1108, 2011.

CVM. Mercado de valores mobiliários brasileiro. 3. ed. Comissão de Valores Mobiliários, 2014. Disponível em: 〈www.cvm.gov.br〉.

CVM. Análise de Investimentos. 1. ed. Comissão de Valores Mobiliários, 2017. Disponível em: 〈www.cvm.gov.br $\rangle$.

FAMA, E. F. Efficient capital markets: A review of theory and empirical work. The Journal of Finance, v. 25, n. 2, p. 383-417, 1970.

FAMA, E. F. Stock returns, expected returns, and real activity. The Journal of Finance, v. 45, n. 4, p. 1089-1108, 1990.

FAMA, E. F.; FRENCH, K. R. The cross-section of expected stock returns. The Journal of Finance, v. 47, n. 2, p. 427-465, 1992.

FAMA, E. F.; FRENCH, K. R. Common risk factors in the returns on stocks and bonds. Journal of Financial Economics, v. 33, n. 1, p. 3-56, 1993.

FAMA, E. F.; FRENCH, K. R. Luck versus skill in the cross-section of mutual fund returns. The Journal of Finance, v. 65, n. 5, p. 1915-1947, 2010. 
FENG, G.; GIGLIO, S.; XIU, D. Taming the factor zoo. University of Chicago. Working paper, 2017.

FILHO, B. G. O.; SOUSA, A. F. Fundos de investimento em ações no Brasil: Métricas para avaliação de desempenho. REGE, v. 22, n. 1, p. 61-76, 2015.

FRANZ, P. R. G.; FIGUEIREDO, A. C. Avaliação da capacidade de market timing dos administradores de fundos mútuos de ações no brasil. Revista de Economia e Administração, v. 2, n. 1, p. 33-46, 2003.

FRIESEN, G. C.; SAPP, T. R. A. Mutual fund flows and investor returns: An empirical examination of fund investor timing ability. Journal of Banking and Finance, v. 31, n. 2796-2816, 2007.

GOETZMANN, W. N.; IBBOTSON, R. G. Do winners repeat? patterns in mutual fund performance. Journal of Portfolio Management, n. 20, p. 9-18, 1994.

GOMES, F. A. R.; CRESTO, V. Avaliação do desempenho dos fundos long-short no Brasil. Revista Brasileira de Finanças, v. 8, n. 4, p. 505-529, 2010.

GORMAN, L.; WEIGAND, R. Measuring alpha based performance:implications for alpha focused, structured products. SSRN Electronic Journal, v. 5, 2009.

GRINBLATT, M.; TITMAN, S. A study of monthly mutual fund returns and performance evaluation techniques. The Journal of Financial and Quantitative Analysis, v. 29, n. 3, p. 419-444, 1994.

GRINBLATT, M.; TITMAN, S.; WERMERS, R. Momentum investment strategies, portfolio performance, and herding: A study of mutual fund behavior. The American Economic Review, v. 85, n. 5, p. 1088-1105, 1995.

GUJARATI, D. N.; PORTER, D. C. Econometria Básica. 5. ed. [S.1.]: AMGH Editora Ltda., 2011.

HAHN, J.; LEE, H. Yield spreads as alternative risk factors for size and book-to-market. Journal of financial and quantitative analysis, v. 41, n. 2, p. 245-269, 2006.

HAUGEN, R. A. The new finance: the case against efficient markets. 5. ed. [S.1.]: Ed. New Jersey: Prentice Hall 146, 1995.

HENDRICKS, J. P. D.; ZECKHAUSER, R. Hot hands in mutual funds: Short-run persistence of relative performance, 1974-1988. The Journal of Finance, v. 48, n. 3389, p. 93-130, 1993.

HSU, J.; KALESNIK, V. Finding smart beta in the factor zoo. 2014. Disponível em: 〈https://www.advisorperspectives.com/commentaries/2014/08/08/ finding-smart-beta-in-the-factor-zoo $\rangle$.

HUIJ, J.; POST, T. On the performance of emerging market equity mutual funds. Emerging Markets Review, v. 12, p. 238-249, 2011.

HUNTER, D. et al. Mutual fund performance evaluation with active peer benchmarks. Journal of Financial Economics, v. 112, p. 1-29, 2014. 
HWANG, S.; RUBESAM, A. Searching the factor zoo. Working paper, 2018. Disponível em: 〈https://papers.ssrn.com/sol3/papers.cfm?abstract_id=3100811〉.

ICI. 2017 Investment Company Fact Book. 57. ed. [S.1.]: Investment Company Institute, 2017.

IIFA. International Investment Funds Association. 2018. Disponível em: $\langle$ https://www.iifa.ca/ $\rangle$.

INSTRUÇÃO. CVM. 555/14. Disponível em: 〈http://www.cvm.gov.br/legislacao/ instrucoes/inst555.html $>$.

JANK, S. Mutual fund flows, expected returns, and the real economy. Journal of Banking and Finance, v. 36, n. 3060-3070, 2012.

JEGADEESH, N.; TITMAN, S. Returns to buying winners and selling losers: Implications for stock market efficiency. The Journal of Finance, v. 48, n. 1, p. 65-91, 1993.

JENSEN, M. C. The performance of mutual funds in the period 1945-1964. The Journal of Finance, v. 23, n. 2, p. 389-416, 1968.

JR., N. C. A. C.; NEVES, M. B. E. Variáveis fundamentalistas e os retornos das ações. Revista Brasileira de Economia, v. 54, n. 1, p. 123-137, 2000.

JUNIOR, D. R. P. Análise do perfil do investidor com base em análise de suas percepções subjetivas de risco e retorno. Revista Cesumar - Ciências Humanas e Sociais Aplicadas, v. 15, n. 1, p. 171-187, 2010.

KACPERCZYK, M.; SIALM, C.; ZHENG, L. Unobserved actions of mutual funds. The Review of Financial Studies, v. 21, n. 6, p. 2379-2416, 2008.

KAHNEMAN, D.; TVERSKY, A. Prospect theory: An analysis of decision under risk. Econometrica, v. 47, n. 2, p. 263-292, 1979.

KILSGÅRD, D.; WITTORF, F. Estimation of Expected Return: The Fama and French Three-factor Model Vs. The Chen, Novy-Marxs and Zhang Three Factor Model. Tese (Doutorado) — Lunds Universitet, 2011.

LAES, M. A.; SILVA, M. E. Performance of mutual equity funds in Brazil - a bootstrap analysis. Revista Economia Anpec, v. 15, n. 1, p. 294-306, 2014.

LEUSIN, L. M. C.; BRITO, R. D. Market timing e avaliação de desempenho dos fundos brasileiros. Revista de Administração de Empresas, v. 48, n. 2, p. 22-36, 2008.

LINTNER, J. The valuation of risk assets and the selection of risky investments in stock portfolios and capital budgets. Review of Economics and Statistics, v. 47, n. 1, p. 13-37, 1965.

MÁLAGA, F. K.; SECURATO, J. R. Aplicação do modelo de três fatores de fama e french no mercado acionário brasileiro: um estudo empírico do período 1995-2003. Encontro Anual da Associação Nacional dos Programas de Pós-Graduação em Administração, v. 28, 2004. 
MARKOWITZ, H. M. Portfolio selection. The Journal of Finance, v. 7, n. 77-91, 1952.

MURAKOSHI, V. Y.; BRITO, R. D. Fatores comuns de risco de mercado, tamanho, valor e diferenciais de juros nos retornos esperados das ações brasileiras. Revista de Economia e Administração, v. 8, n. 2, p. 253-282, 2009.

MUSSA, A.; FAMÁ, R.; SANTOS, O. dos. A adição do fator de risco momento ao modelo de precificação de ativos dos três fatores de fama french aplicado ao mercado acionário brasileiro. REGE, São Paulo, v. 19, n. 3, p. 431-447, 2012.

NERASTI, J. N.; LUCINDA, C. R. Persistência de desempenho em fundos de ações no brasil. Revista Brasileira de Finanças, v. 14, n. 2, p. 269-297, 2016.

NEUMANN, J. V.; MORGENSTERN, O. Theory of Games and Economic Behavior. [S.l.]: Princeton University Press, 1944.

NOVY-MARX, R. The other side of value: The gross profitability premium. Journal of Financial Economics, v. 108, p. 1-28, 2013.

PÁSTOR, L.; STAMBAUGH, R. F. Mutual fund performance and seemingly unrelated assets. Journal of Financial Economics, v. 63, n. 3, p. 315-349, 2002.

PINTO, D. M. A. Desempenho dos fundos de investimento de ações brasileiro, um estudo do período de 2000 a 2014. Dissertação de Mestrado EESP-FGV, 2014.

REBESCHINI, A. M.; LEAL, R. P. C. Stock fund returns and macroeconomic variables in brazil. Latin American Business Review, v. 17:2, n. 139-161, 2016.

ROCHMAN, R. R.; JUNIOR, W. E. Fundos de investimento ativos e passivos no brasil: comparando e determinando os seus desempenhos. Anais do Encontro Nacional da Associação Nacional de Pós-Graduação e Pesquisa em Administração, Salvador, BA, Brasil, v. 30, 2006.

RODRIGUES, A. V.; SOUZA, A. F. Custo do capital próprio em empresas com autofinanciamento positivo. Anais do IV Semead: São Paulo, 1999.

ROSCHEL, C. M. Persistência de desempenho em fundos long-short no Brasil. Tese (Doutorado) - Escola de Economia de São Paulo da Fundação Getúlio Vargas, 2020.

ROSS, S. A. The arbitrage theory of capital asset pricing. Journal of Economic Theory, v. 13, n. 341-360, 1976.

SHAKER, M. A.; ELGIZIRY, K. Comparisons of asset pricing models in the egyptian stock market. Accouting and Finance Research, v. 3, n. 4, p. 24-30, 2014.

SHARPE, W. F. Capital asset prices: A theory of market equilibrium under conditions of risk. The Journal of Finance, v. 19, n. 425-442, 1964.

Sá, G. T. de. Investimentos no mercado de capitais. [S.l.]: Livro Técnico S.A, 1979.

VARGA, G.; BRITO, R. dias. The cross-section of expected stock returns in brazil. Brazilian Review of Finance, v. 14, n. 2, p. 151-187, 2016. 
WERMERS, R. Momentum investment strategies of mutual funds, performance persistence, and survivorship bias. Working paper - Graduate School of Business and Administration, University of Colorado at Boulder, 1997. 


\section{Apêndice A - Dados do histórico recente da indústria de fundos brasileira}

Figura 4 - Patrimônio líquido anual (em milhões de reais)

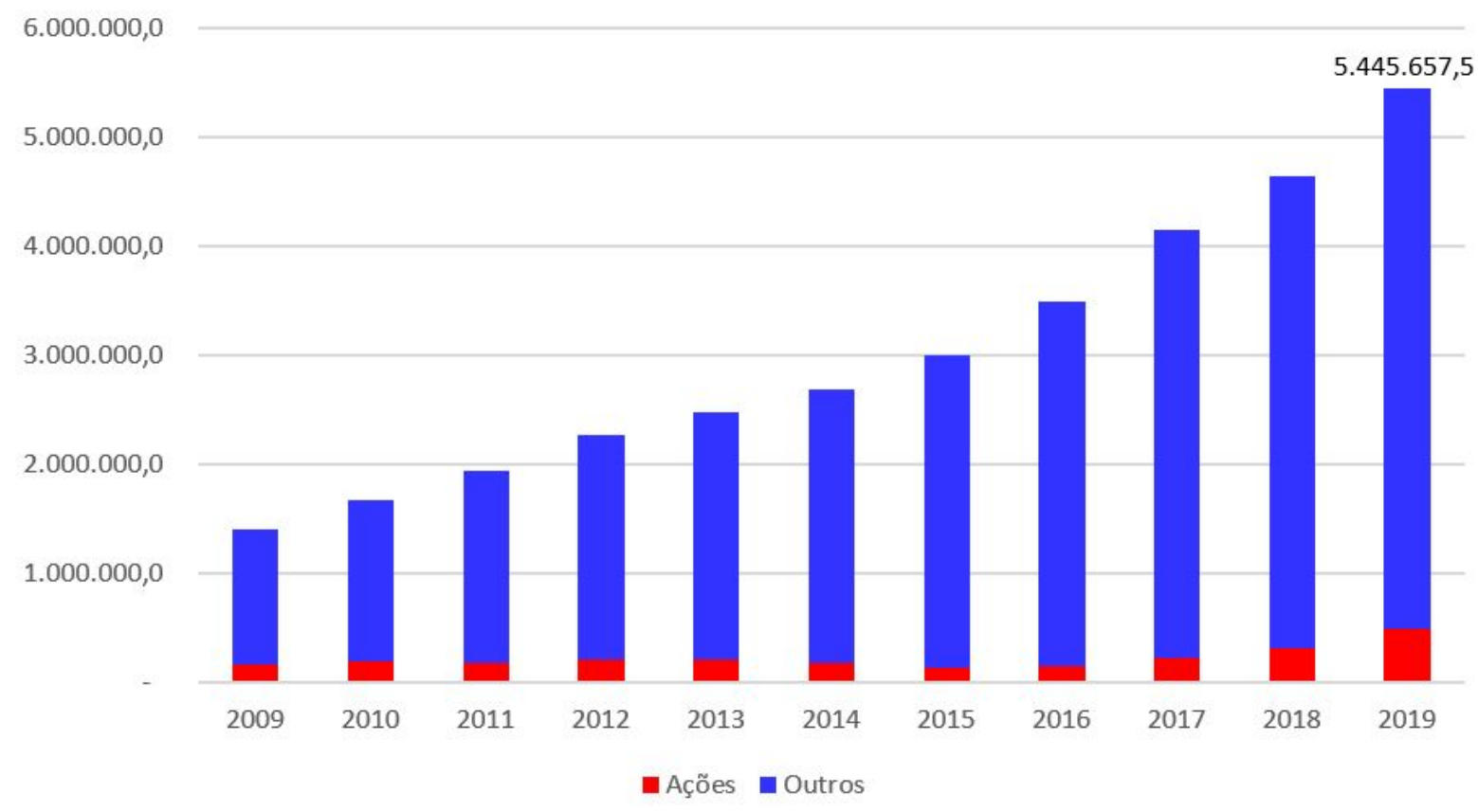

Nota: O valor total do PL da indústria de fundos é a soma de "Ações"e "Outros".

Fonte: Elaboração própria a partir de dados do Consolidado Histórico de Fundos de Investimento, disponibilizado pelo site da ANBIMA.

Figura 5 - Captação líquida anual (em milhões de reais) e taxa CDI

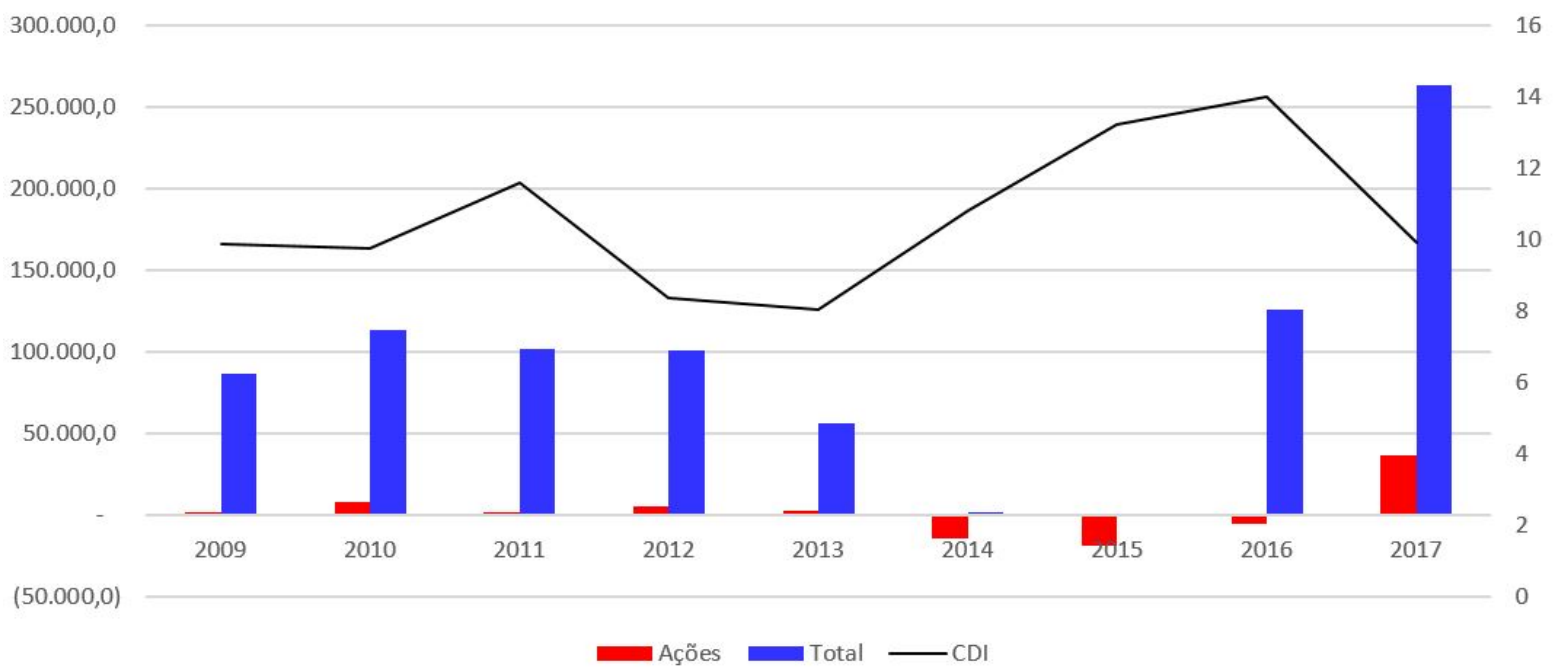

Fonte: Elaboração própria a partir de dados do Consolidado Histórico de Fundos de Investimento, disponibilizado pelo site da ANBIMA. 


\section{Apêndice B - Estrutura da nova classificação de fundos da ANBIMA}

\section{Ativos}

- Valor/Crescimento - Os fundos de "Valor"investem em ações de empresas subvalorizadas, ou seja, que são negociadas a preços mais baixos mas possuem elevado potencial de valorização. Já os fundos de "Crescimento"buscam empresas com perspectiva de manter elevado o ritmo de crescimento.

- Setoriais - Os investimentos são direcionados para empresas do mesmo setor econômico ou setores correlacionados, como agronegócio, petróleo e energia. Constituem uma importante ferramenta do Governo Federal para alavancar alguns setores da economia.

- Dividendos - Fundos que investem em ações de empresas com histórico de pagamento de dividendos (parte do lucro da empresa é dividida entre os acionistas).

- Small Caps - Também usam estratégia de valor, pois devem investir pelo menos 85\% da carteira em empresas com baixa capitalização de mercado, ou seja, empresas que não estão entre as 25 maiores do Índice Brasil (IBRx). Dessa forma, os gestores buscam encontrar empresas subavaliadas, que por algum motivo estão com baixo valor de mercado, mas possuem elevado potencial de valorização.

- Sustentabilidade/Governança - Baseiam seus investimentos em empresas com elevada governança corporativa ou sustentabilidade e responsabilidade social. Os critérios para a definição das ações elegíveis devem estar bem definidos no regulamento desses fundos.

- Índice Ativo - O objetivo de investimento desses fundos é superar índices de mercado como Ibovespa, IBRx ou IBRx -50, em busca de melhor desempenho.

- Livre - Não possuem a obrigação de concentrar sua carteira em alguma estratégia específica. Esses fundos podem investir os recursos em caixa arbitrariamente, necessitando apenas seguir as especificações propostas em seu regulamento.

II. Específicos:

- Fechado de Ações - São fundos de condomínio fechado, ou seja, depois de aberto não é permitida a entrada e saída de cotistas. Dessa forma, suas cotas não 
podem ser negociadas livremente como nos fundos Abertos. O resgate das cotas desses fundos só pode ser feito no fim do período de vigência e portanto, eles possuem um prazo determinado para abertura e fechamento. Como a cobrança de imposto de renda segue tabela regressiva e para esses fundos é feita apenas no momento do resgate das cotas, eles costumam oferecer menor tributação quando comparados aos fundos de condomínio aberto.

- FMP-FGTS - Também chamados de Fundos Mútuos de Privatização, seguem regulamentação em vigor para fundos de pensão. São fundos que aplicam recursos de pessoas físicas com contas vinculadas ao FGTS em empresas privatizadas pelo governo Federal, Estadual ou Municipal.

III. Indexados:

- Índices - Esses fundos investem nas ações mais representativas de algum indicador de referência do mercado, como Ibovespa ou IBrX-50 por exemplo, com o objetivo de replicar o desempenho médio do índice escolhido. A parte dos recursos que não estiver investida em ativos de renda variável deve ser aplicada em cotas de fundos de Renda Fixa. São considerados fundos passivos e por isso costumam garantir menores taxas aos investidores.

IV. Investimento no Exterior:

- Investimento no exterior - Podem investir mais de $40 \%$ do seu patrimônio líquido em ativos no exterior. Esses fundos admitem alavancagem (operar com valores maiores do que seu patrimônio líquido, por meio de empréstimos de curto prazo, visando rentabilidades mais elevadas). 


\section{Apêndice C - Estimações dos modelos CAPM, três fatores de Fama-French e quatro fatores de Carhart por categoria ANBIMA}

Tabela 6 - Categoria Ativos: resultados das regressões para os fundos de ações com modelo CAPM, três fatores de Fama-French e quatro fatores de Carhart

\begin{tabular}{lccc}
\hline \hline VARIÁVEIS & $($ CAPM $)$ & (Fama-French) & (Carhart) \\
\hline RMRF & $0.7810^{* * *}$ & $0.7618^{* * *}$ & $0.7837^{* * *}$ \\
& $(0.0092)$ & $(0.0085)$ & $(0.0082)$ \\
SMB & & $0.1490^{* * *}$ & $0.1873^{* * *}$ \\
& & $(0.0071)$ & $(0.0077)$ \\
HML & & $-0.0603^{* * *}$ & $-0.0554^{* * *}$ \\
& & $(0.0064)$ & $(0.0064)$ \\
WML & & & $0.0638^{* * *}$ \\
& & & $(0.0042)$ \\
Constante & $0.0006^{* * *}$ & $0.0009^{* * *}$ & $0.0001^{* * *}$ \\
& $(0.0000)$ & $(0.0000)$ & $(0.0001)$ \\
\hline Observações & 76,258 & 76,258 & 76,258 \\
R-quadrado & 0.5357 & 0.5465 & 0.5493 \\
Número de fundos & 995 & 995 & 995 \\
AIC & -283617 & -285403 & -285885 \\
BIC & -283608 & -285375 & -285848 \\
R-quadrado-aj & 0.536 & 0.546 & 0.549 \\
\hline \hline
\end{tabular}

Estimação dos modelos CAPM, três fatores de Fama-French e quatro fatores de Carhart por MQO com efeito fixo. A variável dependente é o excesso de retorno. Os erros padrão estão entre parênteses abaixo do parâmetro estimado. A significância estatística de 10\%, $5 \%$ e $1 \%$ está indicada por $* * * \mathrm{e}^{* * *}$, respectivamente. 
Tabela 7 - Categoria Específicos: resultados das regressões para os fundos de ações com modelo CAPM, três fatores de Fama-French e quatro fatores de Carhart

\begin{tabular}{lccc}
\hline \hline VARIÁVEIS & $($ CAPM $)$ & (Fama-French) & (Carhart) \\
\hline RMRF & $1.4483^{* * *}$ & $1.3080^{* * *}$ & $1.1676^{* * *}$ \\
& $(0.0421)$ & $(0.0525)$ & $(0.0480)$ \\
SMB & & -0.0206 & $-0.2628^{* * *}$ \\
& & $(0.0265)$ & $(0.0335)$ \\
HML & & $0.3527^{* * *}$ & $0.3324^{* * *}$ \\
& & $(0.0348)$ & $(0.0344)$ \\
WML & & & $-0.3850^{* * *}$ \\
& & & $(0.0204)$ \\
Constante & $-0.0052^{* * *}$ & $-0.0040^{* * *}$ & $0.0008^{* * *}$ \\
& $(0.0001)$ & $(0.0002)$ & $(0.0003)$ \\
\hline Observações & 9,335 & 9,335 & 9,335 \\
R-quadrado & 0.4370 & 0.4532 & 0.4774 \\
Número de fundos & 98 & 98 & 98 \\
AIC & -19699 & -19967 & -20388 \\
BIC & -19692 & -19946 & -20359 \\
R-quadrado-aj & 0.437 & 0.453 & 0.477 \\
\hline \hline
\end{tabular}

Estimação dos modelos CAPM, três fatores de Fama-French e quatro fatores de Carhart por MQO com efeito fixo. A variável dependente é o excesso de retorno. Os erros padrão estão entre parênteses abaixo do parâmetro estimado. A significância estatística de 10\%, $5 \%$ e $1 \%$ está indicada por $*$, ** $\mathrm{e}^{* * *}$, respectivamente. 
Tabela 8 - Categoria Indexados: resultados das regressões para os fundos de ações com modelo CAPM, três fatores de Fama-French e quatro fatores de Carhart

\begin{tabular}{lccc}
\hline \hline VARIÁVEIS & $($ CAPM $)$ & (Fama-French) & (Carhart) \\
\hline RMRF & $1.0560^{* * *}$ & $1.0363^{* * *}$ & $1.0225^{* * *}$ \\
& $(0.0212)$ & $(0.0201)$ & $(0.0185)$ \\
SMB & & $0.0256^{* * *}$ & 0.0014 \\
& & $(0.0095)$ & $(0.0115)$ \\
HML & & $0.0251^{* * *}$ & $0.0226^{* *}$ \\
& & $(0.0093)$ & $(0.0090)$ \\
WML & & & $-0.0392^{* * *}$ \\
& & & $(0.0061)$ \\
Constante & $-0.0027^{* * *}$ & $-0.0026^{* * *}$ & $-0.0021^{* * *}$ \\
& $(0.0000)$ & $(0.0000)$ & $(0.0001)$ \\
\hline Observações & 4,298 & 4,298 & 4,298 \\
R-quadrado & 0.8782 & 0.8792 & 0.8801 \\
Número de fundos & 49 & 49 & 49 \\
AIC & -21337 & -21367 & -21399 \\
BIC & -21330 & -21348 & -21374 \\
R-quadrado-aj & 0.878 & 0.879 & 0.880 \\
\hline \hline
\end{tabular}

Estimação dos modelos CAPM, 3 Fatores de Fama-French e 4 Fatores de Carhart por MQO com efeito fixo. A variável dependente é o excesso de retorno. Os erros padrão estão entre parênteses abaixo do parâmetro estimado. A significância estatística de 10\%, 5\% e $1 \%$ está indicada por $*, * * \mathrm{e}^{* * *}$, respectivamente. 
Tabela 9 - Categoria Investimento no Exterior: resultados das regressões para os fundos de ações com modelo CAPM, três fatores de Fama-French e quatro fatores de Carhart

\begin{tabular}{lccc}
\hline \hline VARIÁVEIS & $($ CAPM $)$ & (Fama-French) & (Carhart) \\
\hline RMRF & $0.4484^{* * *}$ & $0.4157^{* * *}$ & $0.4336^{* * *}$ \\
& $(0.0521)$ & $(0.0539)$ & $(0.0523)$ \\
SMB & & $0.1347^{* * *}$ & $0.1649^{* * *}$ \\
& & $(0.0287)$ & $(0.0300)$ \\
HML & & -0.0266 & -0.0224 \\
& & $(0.0220)$ & $(0.0218)$ \\
WML & & & $0.0513^{* * *}$ \\
& & & $(0.0168)$ \\
Constante & $0.0031^{* * *}$ & $0.0035^{* * *}$ & $0.0029^{* * *}$ \\
& $(0.0000)$ & $(0.0001)$ & $(0.0002)$ \\
\hline Observações & 8,074 & 8,074 & 8,074 \\
R-quadrado & 0.0706 & 0.0742 & 0.0750 \\
Número de fundos & 126 & 126 & 126 \\
AIC & -16781 & -16807 & -16812 \\
BIC & -16774 & -16786 & -16784 \\
R-quadrado-aj & 0.0705 & 0.0738 & 0.0745 \\
\hline \hline
\end{tabular}

Estimação dos modelos CAPM, três fatores de Fama-French e quatro fatores de Carhart por MQO com efeito fixo. A variável dependente é o excesso de retorno. Os erros padrão estão entre parênteses abaixo do parâmetro estimado. A significância estatística de 10\%, $5 \%$ e $1 \%$ está indicada por $* * * \mathrm{e}^{* * *}$, respectivamente. 